\title{
Are we mis-estimating chemotherapy- induced peripheral neuropathy? Analysis of assessment methodologies from a prospective, multinational, longitudinal cohort study of patients receiving neurotoxic chemotherapy
}

Alex Molassiotis ${ }^{1 *}$ (D), Hui Lin Cheng ${ }^{1}$, Violeta Lopez ${ }^{2}$, Joseph S. K. Au ${ }^{3}$, Alexandre Chan ${ }^{4}$, Aishwarya Bandla ${ }^{5}$, K. T. Leung ${ }^{6}$, Y. C. Li ${ }^{6}$, K. H. Wong ${ }^{6}$, Lorna K. P. Suen ${ }^{1}$, Choi Wan Chan ${ }^{1}$, Janelle Yorke ${ }^{7}$, Carole Farrell ${ }^{7}$ and Raghav Sundar ${ }^{*}$

\begin{abstract}
Background: There are inconsistencies in the literature regarding the prevalence and assessment of chemotherapyinduced peripheral neuropathy (CIPN). This study explored CIPN natural history and its characteristics in patients receiving taxane- and platinum-based chemotherapy.

Patients and methods: Multi-country multisite prospective longitudinal observational study. Patients were assessed before commencing and three weekly during chemotherapy for up to six cycles, and at 6,9, and 12 months using clinician-based scales (NCl-CTCAE; WHO-CIPN criterion), objective assessments (cotton wool test; $10 \mathrm{~g}$ monofilament); patient-reported outcome measures (FACT/GOG-Ntx; EORTC-CIPN20), and Nerve Conduction Studies.

Results: In total, 343 patients were recruited in the cohort, providing 2399 observations. There was wide variation in CIPN prevalence rates using different assessments (14.2-53.4\%). Prevalence of sensory neuropathy (and associated symptom profile) was also different in each type of chemotherapy, with paclitaxel (up to 63\%) and oxaliplatin (up to 71.4\%) showing the highest CIPN rates in most assessments and a more complex symptom profile. Peak prevalence was around the 6-month assessment (up to 71.4\%). Motor neurotoxicity was common, particularly in the docetaxel subgroup (up to 22.1\%; detected by NCI-CTCAE). There were relatively moderately-to-low correlations between scales $\left(r_{s}=0.15, p<0.05-r_{s}=0.48 p<0.001\right)$, suggesting that they measure different neurotoxicity aspects from each other. Cumulative chemotherapy dose was not associated with onset and course of CIPN.

Conclusion: The historical variation reported in CIPN incidence and prevalence is possibly confounded by disagreement between assessment modalities. Clinical practice should consider assessment of motor neuropathy for neurotoxic chemotherapy. Current scales may not be all appropriate to measure CIPN in a valid way, and a combination of scales are needed.
\end{abstract}

Keywords: Peripheral neuropathy, Neurotoxicity, Chemotherapy, Cancer, Assessment, Taxanes, Platins

\footnotetext{
*Correspondence: alex.molasiotis@polyu.edu.hk; raghav_sundar@nuhs.edu.sg

${ }^{1}$ School of Nursing, The Hong Kong Polytechnic University, Hong Kong,

Hong Kong, Special Administrative Region of China

${ }^{8}$ Department of Haematology-Oncology, National University Health System,

Singapore, Singapore

Full list of author information is available at the end of the article
}

(c) The Author(s). 2019 Open Access This article is distributed under the terms of the Creative Commons Attribution 4.0 International License (http://creativecommons.org/licenses/by/4.0/), which permits unrestricted use, distribution, and reproduction in any medium, provided you give appropriate credit to the original author(s) and the source, provide a link to the Creative Commons license, and indicate if changes were made. The Creative Commons Public Domain Dedication waiver (http://creativecommons.org/publicdomain/zero/1.0/) applies to the data made available in this article, unless otherwise stated. 


\section{Background}

Chemotherapy- induced peripheral neuropathy (CIPN) is one of the major dose-limiting side effects of many chemotherapeutic agents including platinum analogues, vinca alkaloids, and taxanes [1]. The structure and function of peripheral motor, sensory and autonomic neurons are affected, causing peripheral neuropathic signs and symptoms [2]. In a systematic review of 31 studies $(N=4179)$, CIPN prevalence was $68.1 \%$ at the first month of chemotherapy to $30 \%$ six-months after chemotherapy, with wide variance in prevalence from 12.1-96.2\%, depending on different timings of assessment and type of chemotherapy, and many assessing CIPN as part of a drug trial or with studies being cross-sectional [3].

What is already known is that neuropathic symptoms tend to progress during chemotherapy and generally regress once treatment stops; symptoms can consist of a mixture of motor, sensory, and autonomic signs; and the pain associated with CIPN can be prolonged and severe, and its treatment is usually difficult [3-5]. Furthermore, neuropathy can have a negative impact on patient's quality of life [4]. Studies showed that CIPN is associated with fatigue, psychological distress and decline in physical independence [6-10]. CIPN may have an impact on the patients' ability to work [11] and is associated with significantly higher medical costs $(\$ 17,344$ more/patient) and higher healthcare utilization than non-CIPN patients [12].

It is clear in the literature that the assessment of CIPN is suboptimal [6]. A recent study using a Delphi technique in a small number of clinicians and consumers showed that there is no consensus as to the best assessment method for CIPN [13]. The NCI Common Toxicity Criteria (CTC) assessment for neuropathy may overestimate the presence of motor neuropathy and misdiagnose CIPN [14], although a consensus meeting suggested that the NCI CTC has good intra/interrater scores and validity [15]. Haryani et al. [16] reviewed available scales and suggested that the FACT-COG-Ntx scale and the Total Neuropathy Scale (TNS) as psychometrically optimal scales out of 20 tools examined. In another study, the Patient Neurotoxicity Questionnaire (PNQ) and the TNS were recommended [13]. The PNQ in particular seems to have received extensive evaluation in response to identified assessment problems with high variance and lack of reliability and concordance of past scales [1, 17-20], and was recommended as a patient-reported outcome preferred tool by another study [13]. It is also clear that there is a significant discrepancy between clinician-rated CIPN through available tools and patient-reported outcome scales, with clinicians under-estimating the severity of CIPN [19]. Another study showed that EORTC-CIPN20 scores may not be reliably converted to CTCAE scores [21]. While the NCI CTC score is generally considered unreliable [6], it has shown significant correlations with the more accepted and reliable TNS [22]. There are multiple studies on this topic, all providing different and often contradictory views on the most appropriate CIPN assessment method, with no 'gold standard' consensus being reached yet.

Longitudinal studies to systematically determine the incidence, severity and natural history of CIPN with different neurotoxic chemotherapy drugs are vital in order to quantify the extent of the problem and inform future design of interventional studies; such studies are uncommon in the literature [23]. Also, prevalence may be linked with the particular assessment scale used in each study, and the sensitivity of scales to detect CIPN is variable in the literature. While some assessment tools have received significant attention in the literature (most with variable reliability/validity issues as mentioned above), there may be other tools that can be utilised in the assessment of CIPN and have received minimal attention that are however used in other areas of medicine effectively (ie. in assessing diabetic neuropathy, etc). Hence, the present study aims to identify the natural history and progression of CIPN within different chemotherapy drugs for up to 12 months after the patient's first infusion of chemotherapy and to analyse consistency of different assessment methods, including the introduction of some more novel approaches in CIPN assessment in detecting prevalence.

\section{Methods \\ Design}

Multinational prospective longitudinal observational cohort study over 12 months from the patient's first neurotoxic chemotherapy infusion.

\section{Sample and settings}

The sample included a heterogeneous group of consecutive patients receiving neurotoxic chemotherapy as inpatients or outpatients in three large hospitals in Hong Kong, Singapore, and Manchester, UK.

\section{Inclusion criteria}

- Cancer patients who are neurotoxic chemotherapynaïve and about to receive taxane- and/or platinumbased chemotherapy

- estimated survival of at least 12 months (as judged by the clinicians)

- aged $18+$ years

- able to give written informed consent 


\section{Sampling and procedures}

Eligible patients were identified by convenient sampling and were approached at the outpatients' clinics by a designated researcher consecutively if they met inclusion criteria. Patients were provided with detailed information about the study. Those who agreed to participate and provided signed consent completed all the baseline measurements and CIPN toxicity assessment at different time intervals. The researchers who carried out the toxicity assessments had undertaken training in neurological assessments beforehand and were provided with a set of standardized guiding questions regarding the grade of toxicity, in order to maintain consistency. Clinical data were obtained from the patients' medical records. The study was approved by all participating hospitals and their respective ethics committees.

\section{Outcome measures}

All assessments were carried out at baseline, at the end of each chemotherapy cycle (before or on day 1 of each chemotherapy cycle) for up to six cycles, and at 6, 9 and 12 months after enrollment into the study.

The NCI-CTCAE is a clinician-based grading system that includes criteria and definitions for quantifying the severity of CIPN in both sensory and motor components, utilizing a 5-point scale [grade 1 (asymptomatic) to grade 5 (death)]. A score of $>/=2$ was deemed indicative of CIPN.

The WHO-CIPN criterion is also a clinician-based grading system, which includes paresthesias, reflex decreases and extent of motor loss as parameters [24], with scores from 0 (none) to 4 (paralysis). A score of $>/=1$ was deemed indicative of CIPN.

Additionally, a neurological examination (deep tendon reflexes; pin sensation; strength) supplemented with a list of questions as mentioned earlier were also used to derive to the scoring of the above two scales.

Sensory examination was conducted by a research team member using: a) cotton wool to lightly touch the patient's hands and feet bilaterally with the patients eyes closed at five points in each limb and b) $10 \mathrm{~g}$ monofilament test in five points in each limb which is a commonly used test in detecting diabetic neuropathy [25]. Hypo/hyperesthesia in most points touched was deemed indicative of CIPN.

Patient-reported outcome measures: For the current analysis, only the four items on numbness/tingling in hands/feet were used from the neuropathy modules of: a) The Functional assessment of cancer therapy (FACT/ GOG-Ntx) [26, 27]. b) The EORTC-QLQ-C30 with its CIPN20 module [28].

Of the main study cohort, a sub-group of patients consented to nerve conduction studies (NCS) as a mode of measurement of CIPN. Each patient underwent NCS of the upper and lower limbs for assessment of neuropathy at three time points: before $\left(\mathrm{NCS}_{\text {baseline }}\right)$, at the end of treatment $\left(\mathrm{NCS}_{\text {end }}\right)$ and 3 months post-treatment $\left(\mathrm{NCS}_{3 \mathrm{~m}}\right)$. Sensory nerve action potential (SNAP) amplitudes and conduction velocities were measured in the bilateral medial, ulnar and radial nerves [29]. Compound motor action potential (cMAP) amplitudes and motor nerve conduction velocities were evaluated in the bilateral sural, saphenous, superficial peroneal, common peroneal and tibial nerves [30].

\section{Data analysis}

Descriptive statistics were used to summarise the data. Prevalence estimates were calculated using 95\% CIs of the percentage of patients with CIPN. Spearman correlations were used to examine the interrelationships among CTCAE-sensory, CTCAE-motor, monofilament, and $\mathrm{WHO}$ criterion. The dose-response relationships between cumulative chemotherapy dose and CIPN were visualized using restricted cubic splines, and the exact dose-response equations were estimated using segmented regression models. The dose-response relationship analysis was performed using R3.3.0 and the remaining statistical analysis was performed using SPSS v.23.0.

\section{Results}

\section{Sample characteristics}

The sample included 343 patients being assessed up to a maximum of 10 times over 12 months (total $=2399$ assessments); 213 were recruited from Hong Kong, 94 from Singapore and 36 from Manchester, UK. They were at a mean age of 55.15 years old $(\mathrm{SD}=9.4$; range $=33-79$ ). Furthermore, 33 subjects completed the $\mathrm{NCS}_{\text {baseline }}$ and $\mathrm{NCS}_{\text {end }}$ assessments, out of which 22 also completed the $\mathrm{NCS}_{3 \mathrm{~m}}$. Among the patients who completed the NCS, 28 were female (85\%), at a median age of 54 years and were receiving primarily Taxol (85\%) and platinum-based chemotherapy (15\%). Other overall sample characteristics are shown in Table 1.

\section{Prevalence of CIPN}

CIPN prevalence rates identified by different measurement tools varied significantly, and occurrence of CIPN peaked at different times. CIPN peak prevalence rates were $17.5 \%$ for the CTCAE motor criterion and $14.2 \%$ for the CTCAE sensory criterion at cycle $6 ; 30.3 \%$ for the WHO criterion at cycle $5 ; 13.4 \%$ for the cotton wool test at 6-month follow-up; $19.4 \%$ for the monofilament test at 6-month follow-up; 44.9-53.4\% for the EORTC-CIPN20 items at cycle 6 , and $46.3-49.6 \%$ at cycle 6 and 6-month follow-up (Table 2 and Fig. 1). 
Motor symptoms were slightly more frequently reported than sensory symptoms (as per CTCAE).

In the taxane-based group, there was a sharp increase soon into the 3rd-5th chemotherapy cycles, and rates remained high across subsequent follow-up, with only a noticeable decrease at the 12-month follow-up (Fig. 2). and peak rates ranging, depending on the scale used, from 13.1\% (cotton wool; 9MFU),

Table 1 Socio-demographic and clinical characteristics of the participants $(N=343)$

\begin{tabular}{|c|c|c|}
\hline Characteristic & $\mathrm{N}$ & $\%$ \\
\hline \multicolumn{3}{|l|}{ Sex } \\
\hline Male & 87 & 25.4 \\
\hline Female & 256 & 74.6 \\
\hline \multicolumn{3}{|l|}{ Ethnicity } \\
\hline Chinese & 269 & 78.4 \\
\hline Non-Chinese Asian & 31 & 9.0 \\
\hline Caucasian & 43 & 12.5 \\
\hline \multicolumn{3}{|l|}{ Cancer diagnosis } \\
\hline Breast cancer & 174 & 50.7 \\
\hline Lung cancer & 48 & 14.0 \\
\hline Gynecological cancer & 46 & 13.4 \\
\hline Head \& Neck cancer & 30 & 8.7 \\
\hline Gastrointestinal cancer & 29 & 8.5 \\
\hline Urinary tract cancer & 16 & 4.7 \\
\hline \multicolumn{3}{|l|}{ Cancer stage } \\
\hline । & 52 & 15.2 \\
\hline$\|$ & 99 & 28.9 \\
\hline III & 116 & 33.8 \\
\hline IV & 76 & 22.2 \\
\hline \multicolumn{3}{|l|}{ Treatment intent } \\
\hline Curative & 250 & 72.9 \\
\hline Definitive & 30 & 8.7 \\
\hline Palliative & 63 & 18.4 \\
\hline \multicolumn{3}{|l|}{ Type of chemotherapy } \\
\hline Taxane & 155 & 45.2 \\
\hline Platinum & 109 & 31.8 \\
\hline Combination of taxane plus platinum & 79 & 23.0 \\
\hline \multicolumn{3}{|l|}{ Chemotherapy protocol } \\
\hline Docetaxel & 122 & 35.6 \\
\hline Paclitaxel & 33 & 9.7 \\
\hline Cisplatin/Carboplatin & 80 & 23.4 \\
\hline Oxaliplatin & 28 & 8.3 \\
\hline Carboplatin+Paclitaxel & 49 & 14.4 \\
\hline Carboplatin+Docetaxel & 29 & 8.6 \\
\hline
\end{tabular}

19.5\% (CTCAE-sensory, 6MFU), 20.3\% (CTCAE-motor, 6MFU), 32.2\% (WHO, cycle5), 43.1-47.2\% (FACT/COG-Ntx, 6MFU) to 42.3-54.9\% (EORTC, cycle 6 \& $6 \mathrm{MFU})$. In the platinum-based group, CIPN levels were relatively low, often being established very early (cycles 2-3) (Fig. 3). In the combination groups, noticeable increases were around cycles 3-6, decreasing significantly after the 6-month follow-up (Fig. 4). Severe CIPN scores (ie. $>/=3$ in CTCAE; $>/=2$ in WHO scale) accounted for a very small number (highest 3.9\%) of patients at 6-month follow-up, although this was up to $22.9 \%$ at cycle 6 using the EORTC-CIPN20 numbness item (hands/fingers).

Within chemotherapy categories, different chemotherapy types produced differential neurotoxicity. In the taxane group, motor dysfunction was more prevalent in the docetaxel subgroup with a steady increase over cycles, with highest prevalence at 9 months (21.3\%), whereas the paclitaxel subgroup showed significantly lower prevalence (Table 3 \& Fig. 5a-f). The opposite was true for sensory dysfunction, where the paclitaxel subgroup had substantially higher rates of sensory problems than the docetaxel subgroup, and at times of certain assessments the difference was 5-10 times more (Table 3 \& Fig. 5a-f). When paclitaxel was combined with carboplatin, again the rates of CIPN were significantly higher in this subgroup than docetaxel plus carboplatin (Table 3 \& Fig. 5a-f). The prevalence varied significantly from scale to scale used for the assessment. From the clinician-based assessment (supplemented by neurological examination), highest prevalence was identified with the WHO-CIPN item followed by the use of monofilament. The patient-reported outcome measures showed significantly higher prevalence than any clinicianbased measures; to note, these scales, unlike the clinician-based ones, also showed a considerable number of patients who reported symptoms indicative of CIPN at the baseline assessment (3.2-21.4\%) (Table 3 \& Fig. 5a-f). Looking at the PRO descriptors of CIPN (using the 9-month assessment, with all other assessments being very similar), typically patients with paclitaxel or oxaliplatin had a higher incidence than other protocols in terms of tingling in the hands/fingers ( 42.9 and $47.1 \%$ respectively vs $3.6-14.4 \%$ ); tingling in the feet/toes (42.9 and $52.9 \%$ respectively vs $0-15.6 \%)$; burning pain in hands/feet/fingers/toes (23.8 and $23.5 \%$ respectively vs $0-9.5 \%$ ); dizziness (19 and $17.6 \%$ respectively vs $3.6-8.9 \%$ ); or blurred vision (38.1 and $35.3 \%$ respectively vs $10.7-27.8 \%$ ). Cramps in the hands were more common in the carboplatin/ cisplatin subgroup (19 and $23.5 \%$ respectively) while cramps in the feet were more common in the paclitaxel (28.6\%) and oxaliplatin (29.4\%) subgroup. 


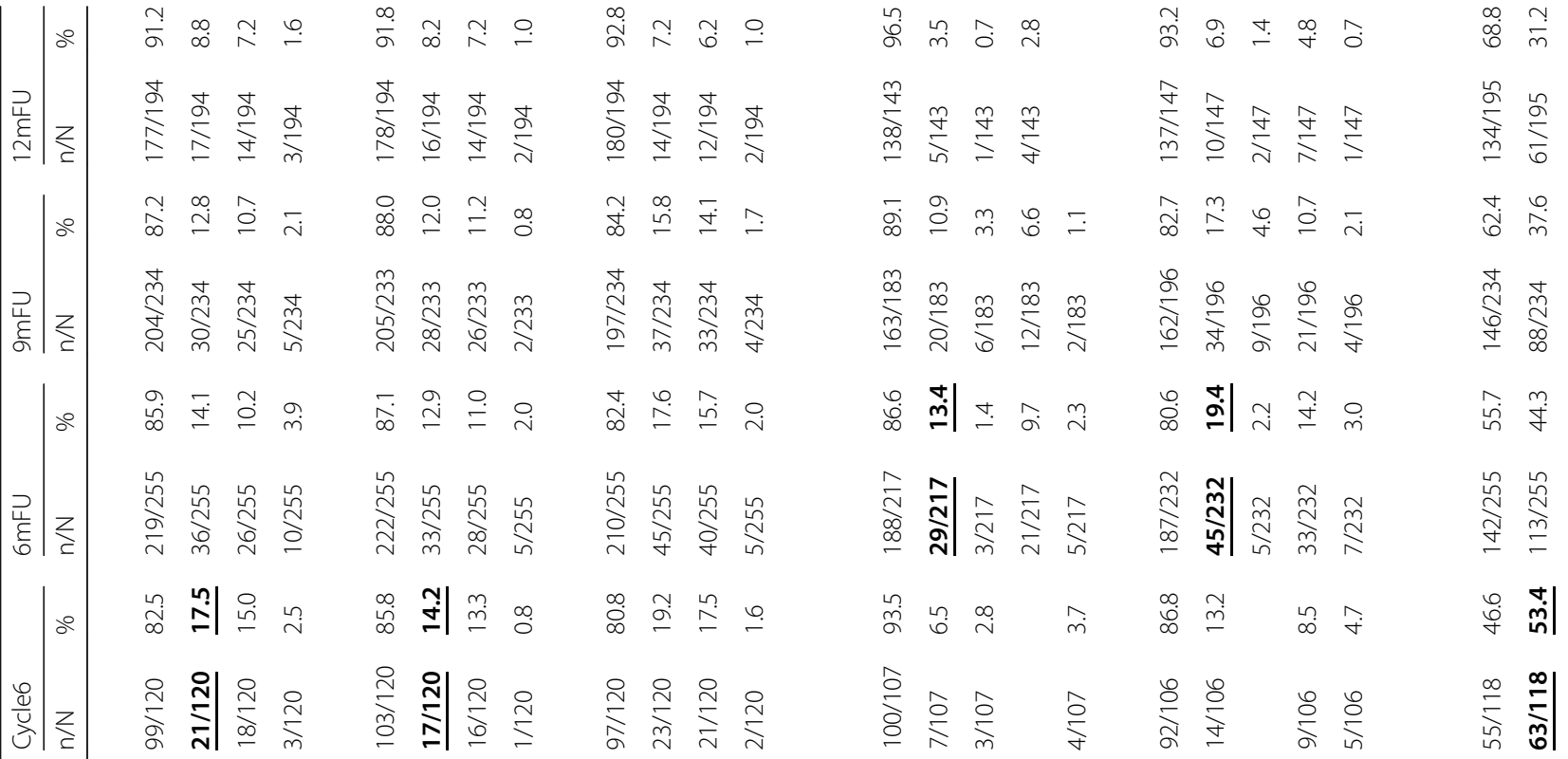

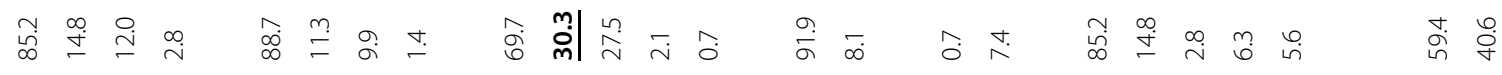

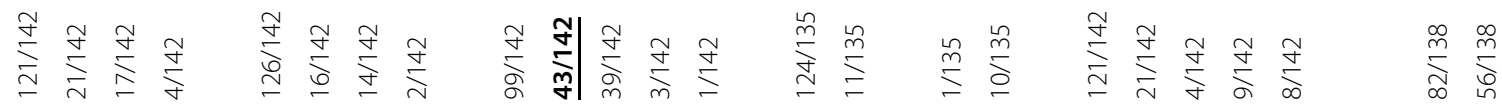

苑

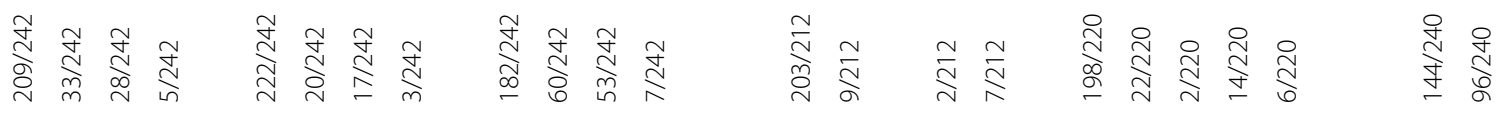

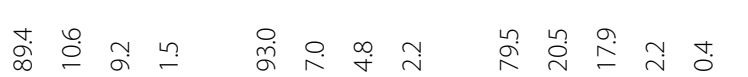

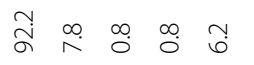

হं

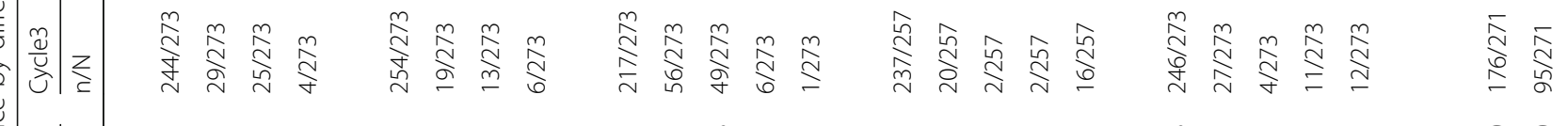

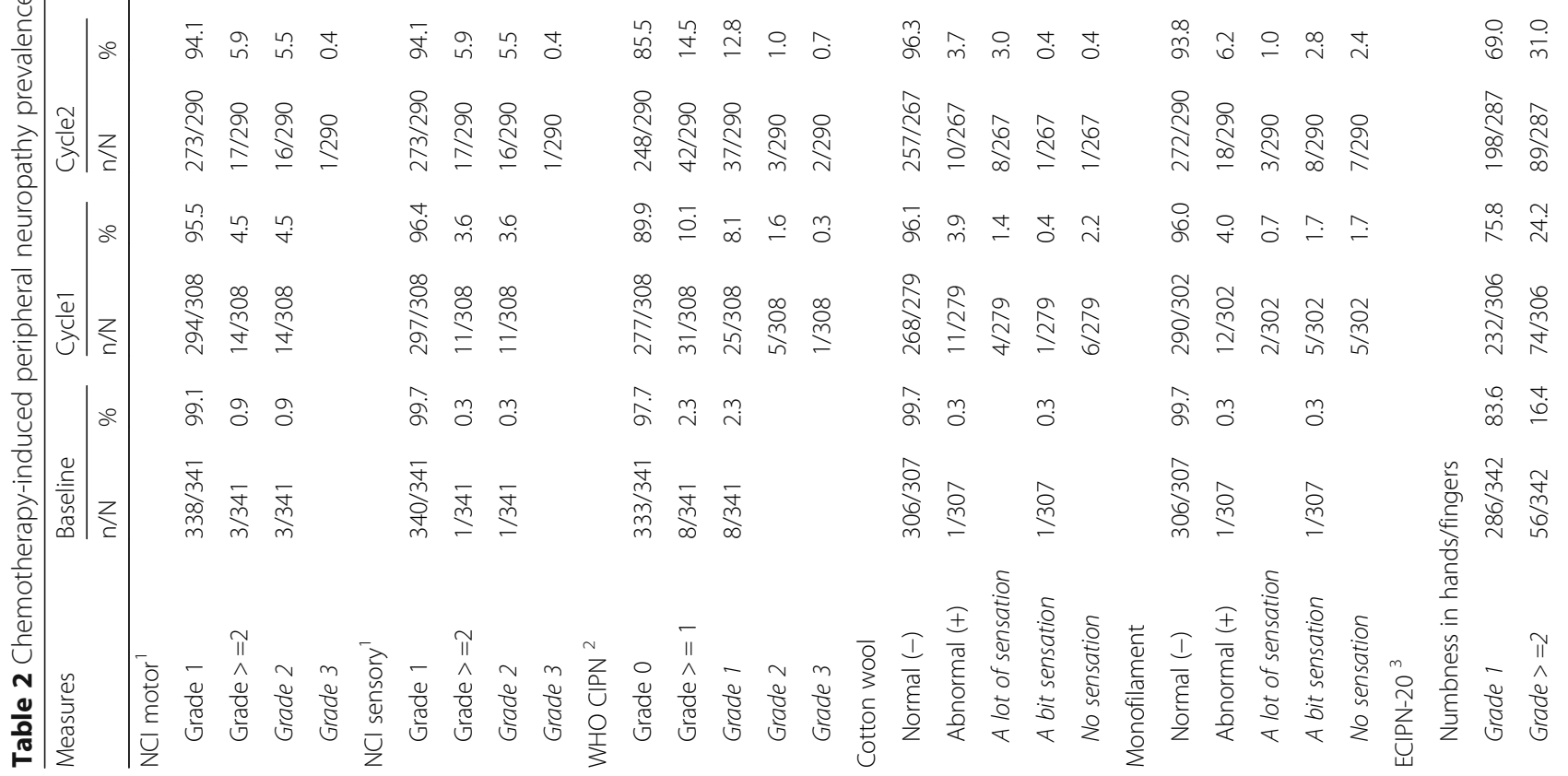




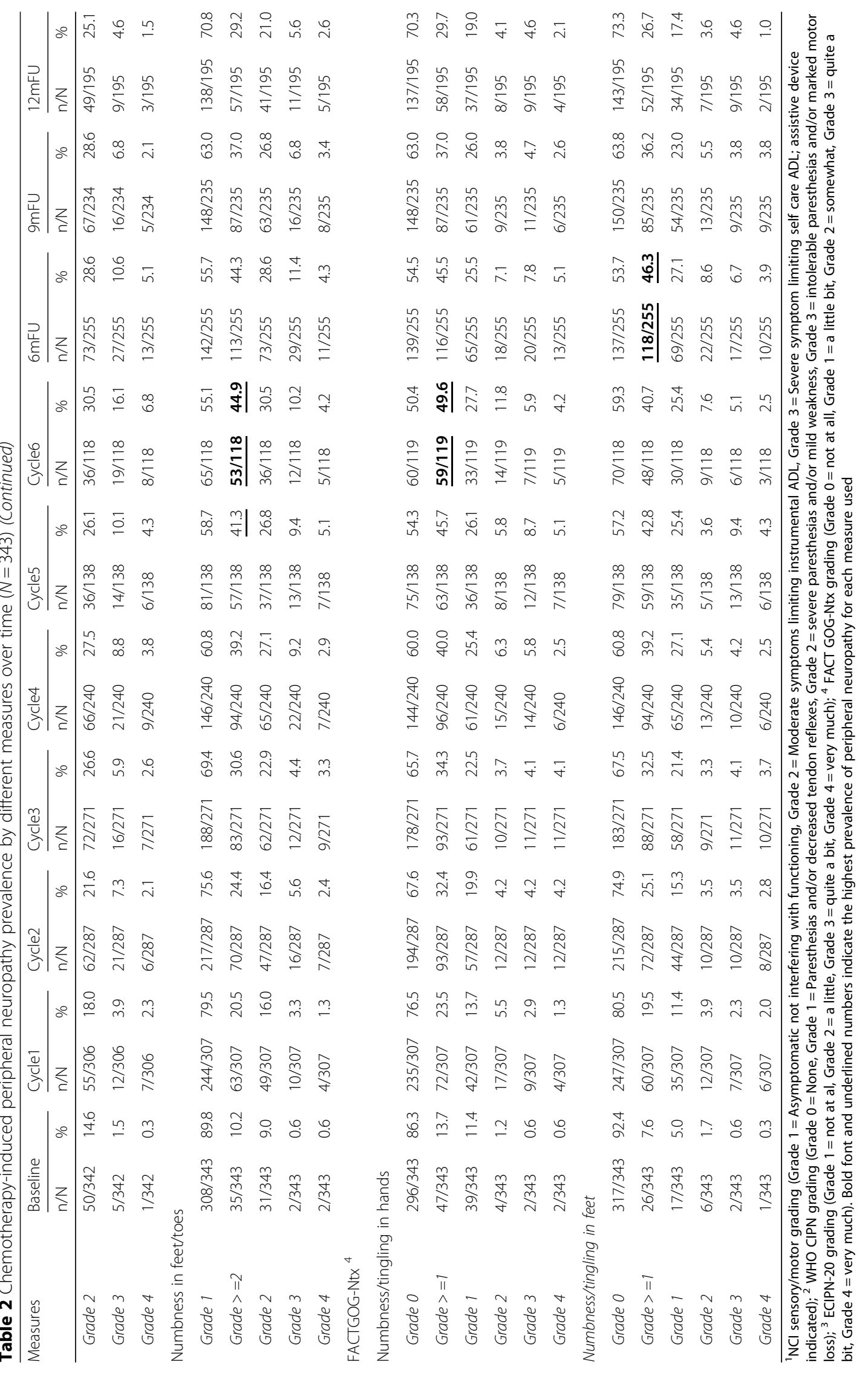


Hearing problems were reported more often in the cisplatin/carboplatin subgroup (28.6\%). Maintaining erection was reported primarily by the docetaxel subgroup (85.7\%) and carboplatin/cisplatin subgroup $(50 \%)$.

\section{Cumulative chemotherapy dose and CIPN}

Figures 6a-e show the dose-response relationship in different chemotherapy agents. No relationship was found for CIPN increases relative to the agent's cumulative dose (Table 4). In most agents CIPN was established early in the treatment and continued to increase or remained relatively stable irrespective of the cumulative dose. This analysis was followed by a segmented regression for each chemotherapy agent, and again this showed no cumulative dose relationship with CIPN, with the exception of cisplatin-based regimens $(=362$ observations). In the latter, the turning point for motor CIPN (using CTCAE) was a dose of $249 \mathrm{mg} / \mathrm{m} 2(p<0.001)$ and for sensory CIPN was $234 \mathrm{mg} / \mathrm{m} 2(p<0.05)$, with lower cumulative dose than the turning point being linked with lower CIPN, and higher cumulative dose than the turning point not being associated with any higher CIPN.

\section{Correlations between scales}

Among the four clinician-based diagnostic scales, correlations were moderate to low at best. Often scales were not correlated with each other, and they were showing somewhat stronger correlations in later assessments, when CIPN was more well-established. The WHO criterion had correlations of $\mathrm{r}_{\mathrm{s}}=0.21-0.37(\mathrm{p}<0.001)$ with the other scales at baseline and highest at 9-month $\left(\mathrm{r}_{\mathrm{s}}=0.44-0.65, p<0.001\right)$ and 12-month $\left(\mathrm{r}_{\mathrm{s}}=0.40-0.59, p<0.001\right)$ assessment. The WHO criterion was correlated more with the (sensory) monofilament assessment $\left(\mathrm{r}_{\mathrm{s}}=0.21-0.68, p<0.001\right)$ and had low to moderate correlations $\left(\mathrm{r}_{\mathrm{s}}=0.15, p<0.05-\mathrm{r}_{\mathrm{s}}=0.48\right.$, $p<0.001)$ with the sensory CIPN CTCAE.

\section{Nerve conduction study (NCS)}

Patients treated with taxane chemotherapy showed a substantial decrease in SNAP (sensory) amplitudes at $\mathrm{NCS}_{\text {end }}\left(35.52 \pm 4.48 \%\right.$ lesser compared to $\left.\mathrm{NCS}_{\text {baseline }}\right)$. Specifically, the SNAP amplitudes of the upper limbs were affected nearly twice as much as the lower limbs $\left(42.79 \pm 3.90 \%\right.$ and $26.71 \pm 8.45 \%$ lower than $\mathrm{NCS}_{\text {baseline}}$, respectively). In contrast, the cMAP (motor) amplitudes of the lower limbs showed substantial decrease at $\mathrm{NCS}_{\text {end }}$, compared to the upper limbs $(17.42 \pm 6.51 \%$ and $1.87 \pm 2.23 \%$ lower than $\mathrm{NCS}_{\text {baseline, respectively). }}$ Compared to the amplitudes, the sensory and motor velocities displayed a minor decrease at $\mathrm{NCS}_{\text {end }}(1.54 \pm 2.52 \%$ and $2.05 \pm 1.63 \%$ lower than $\mathrm{NCS}_{\text {baseline, respectively) }}$ (Fig. 7).

At 3 months post chemotherapy, i.e. $\mathrm{NCS}_{3 \mathrm{~m}}$, patients continued to demonstrate a large decrease in SNAP amplitudes (a further decrease of $7.79 \pm 7.05 \%$ lower than $\left.\mathrm{NCS}_{\text {end }}\right)$. It is to be noted that the upper limbs $(4.85 \pm$ $8.15 \%$ lower than $\mathrm{NCS}_{\text {end }}$ ) had better recovery compared to the lower limbs $\left(18.33 \pm 13.97 \%\right.$ lower than $\left.\mathrm{NCS}_{\text {end }}\right)$.

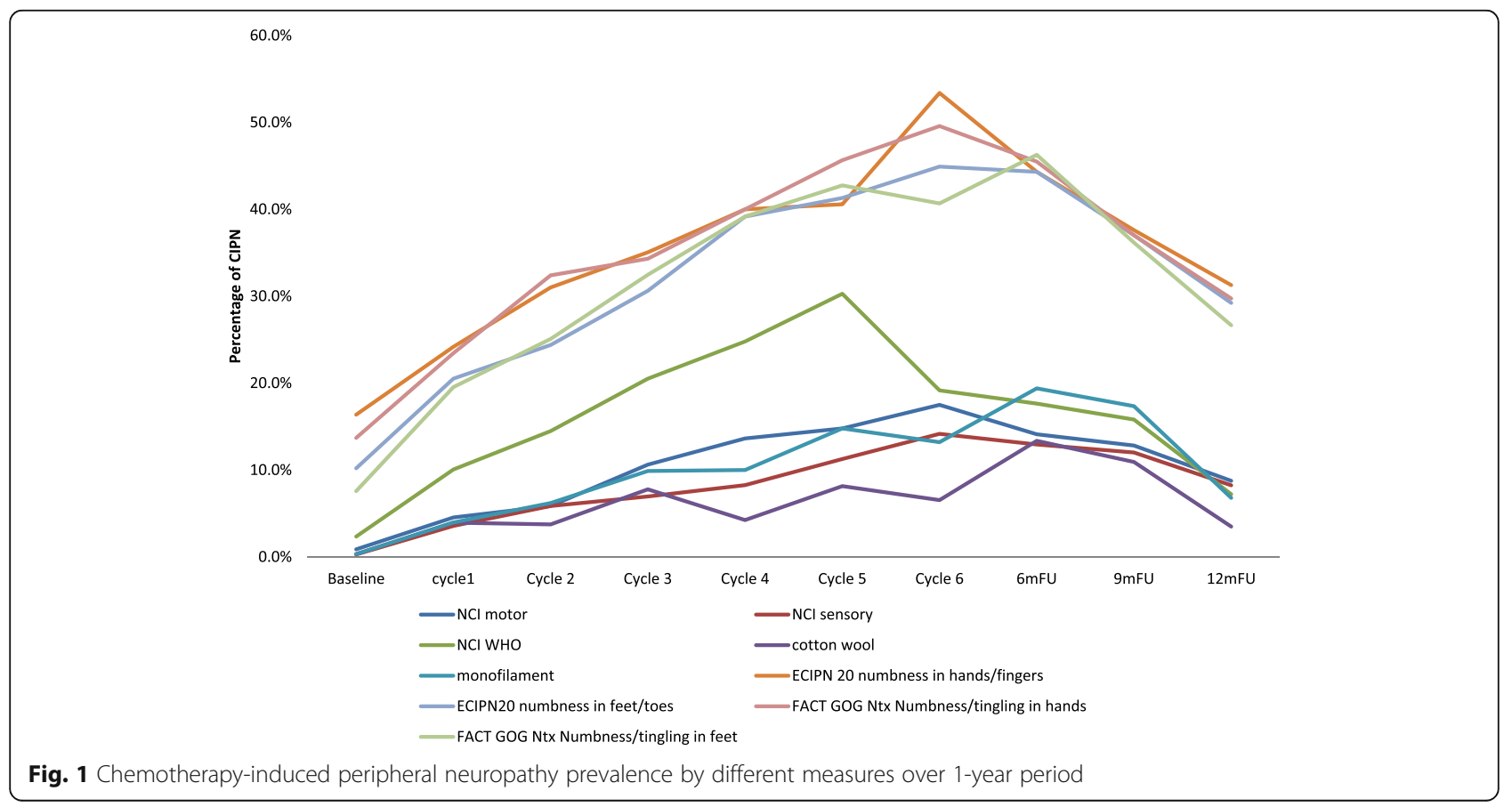



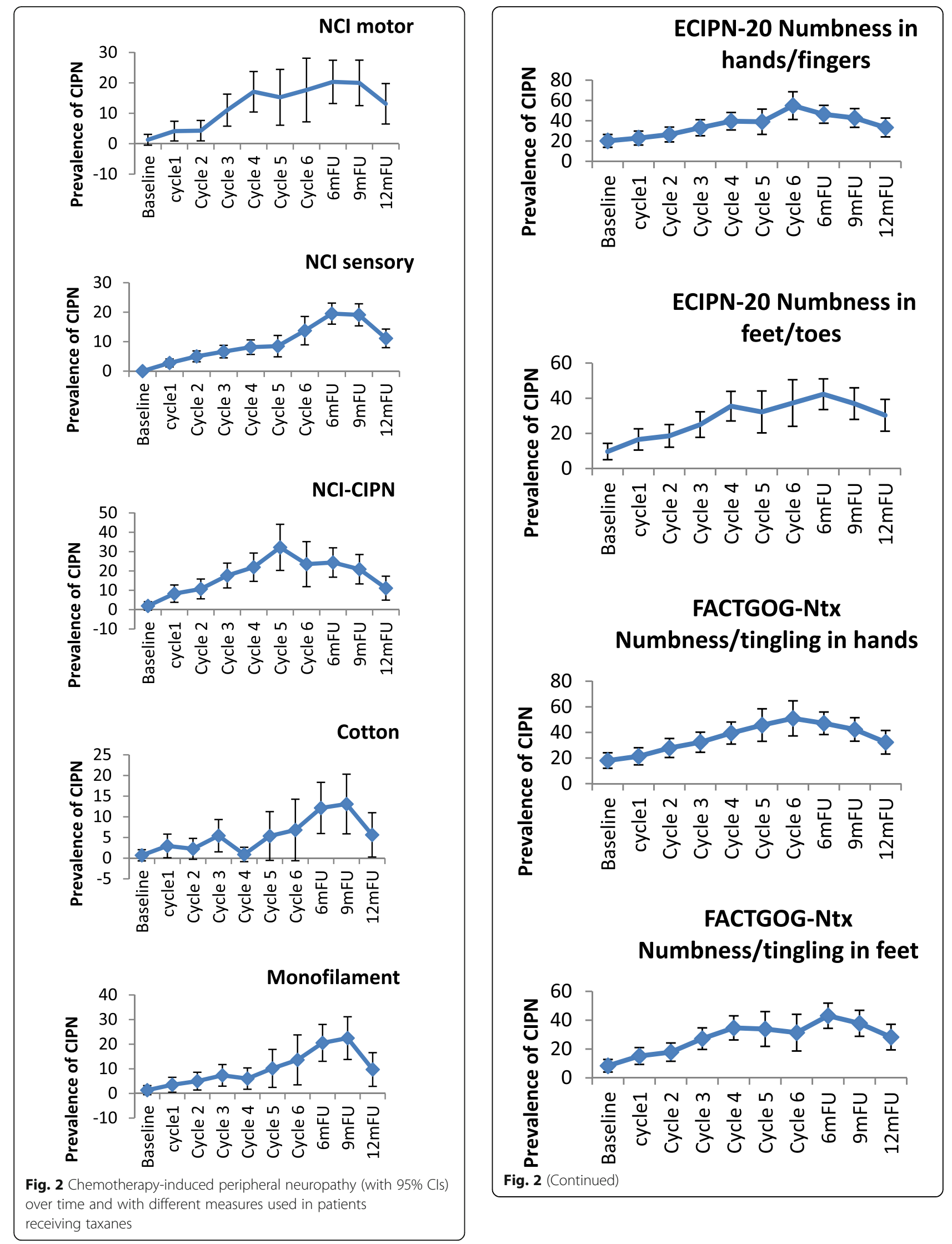


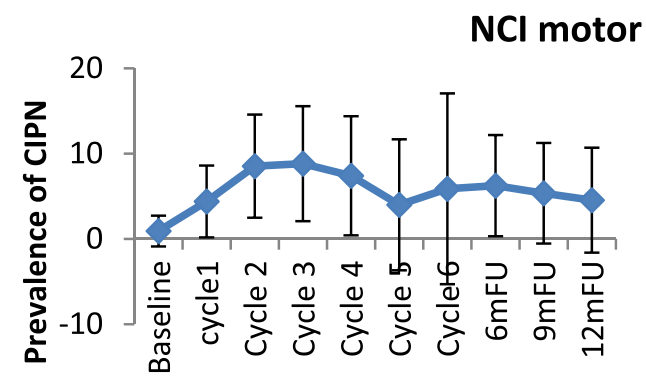

$\mathrm{NCl}$ sensory
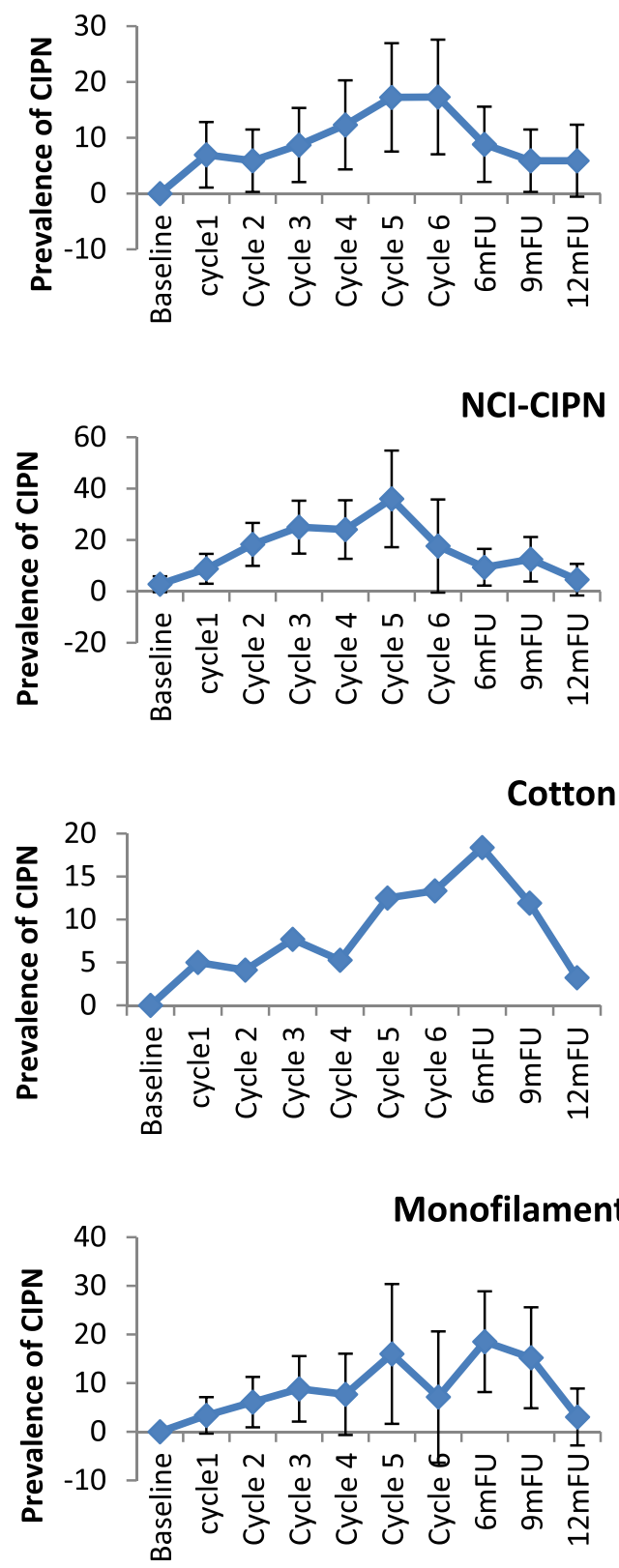

Fig. 3 Chemotherapy-induced peripheral neuropathy (with 95\% Cls) over time and with different measures used in patients receiving platinum chemotherapy

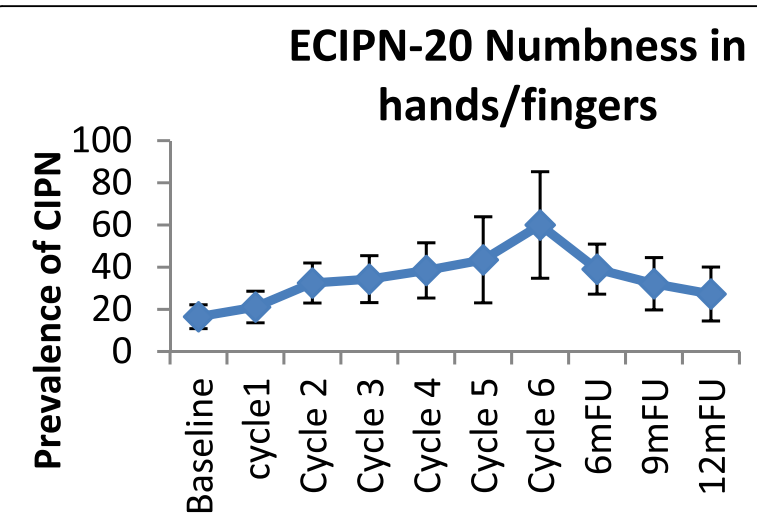

ECIPN-20 Numbness in feet/toes

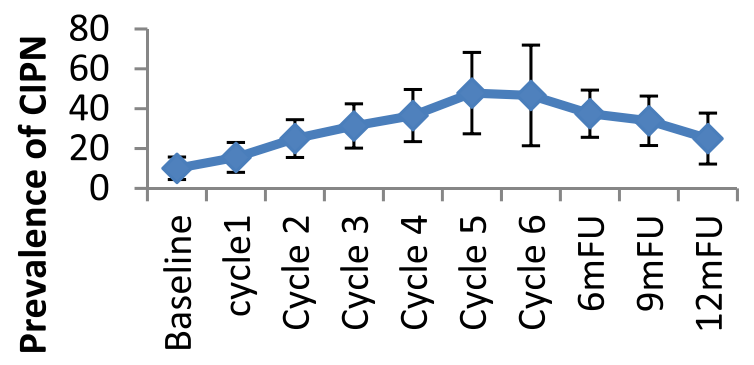

FACTGOG-Ntx

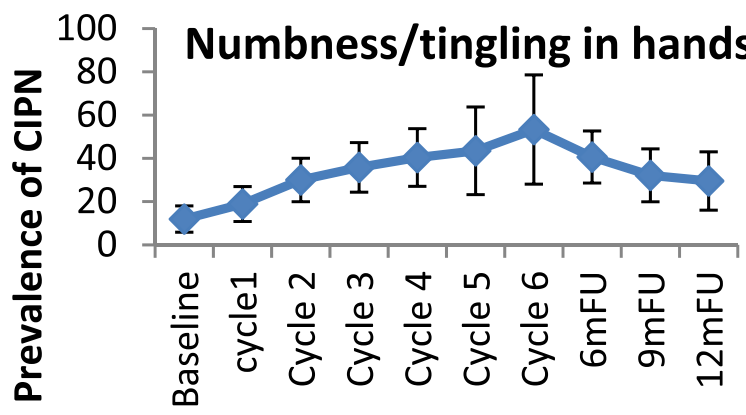

FACTGOG-Ntx Numbness/tingling in feet

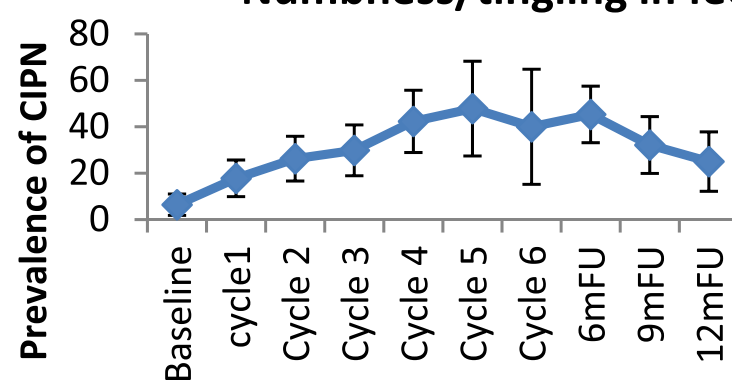

Fig. 3 (Continued) 

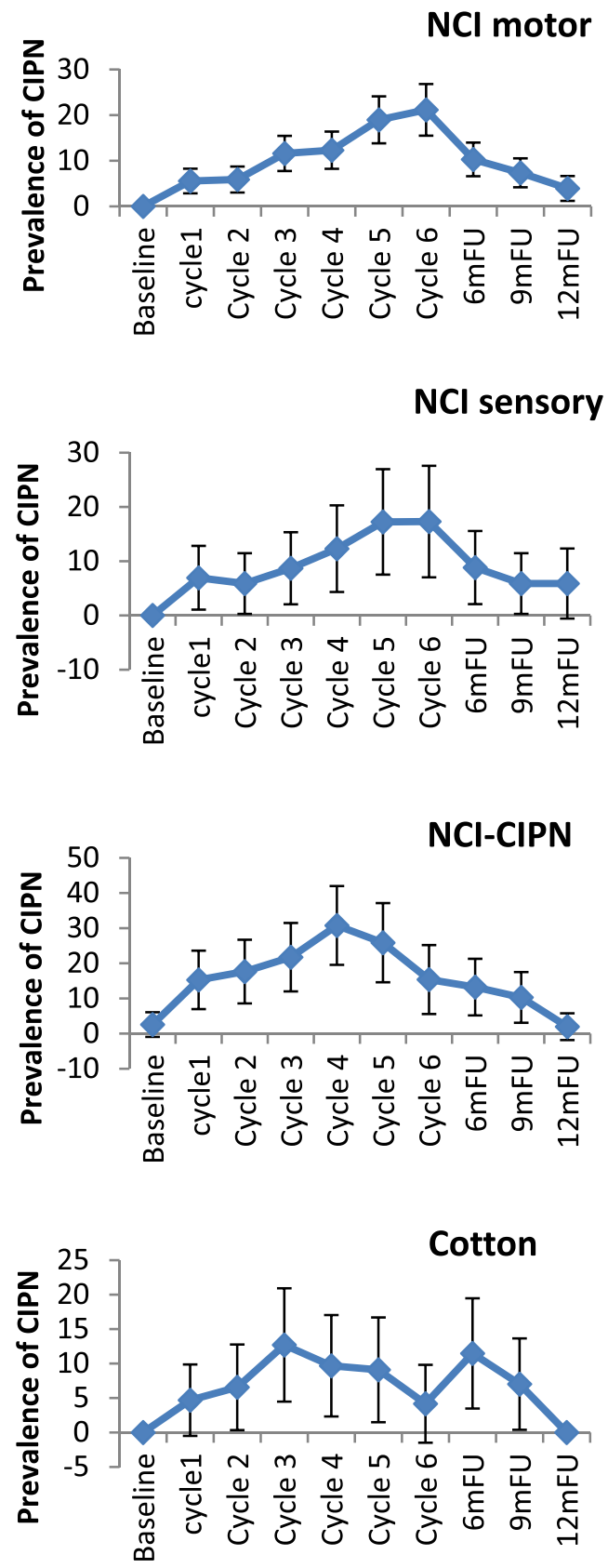

Monofilament

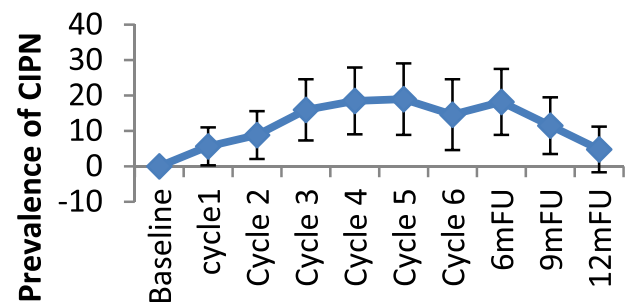

Fig. 4 Chemotherapy-induced peripheral neuropathy (with 95\% Cls) over time and with different measures used in patients receiving combination chemotherapy with taxanes and platinum
ECIPN-20 Numbness in hands/fingers

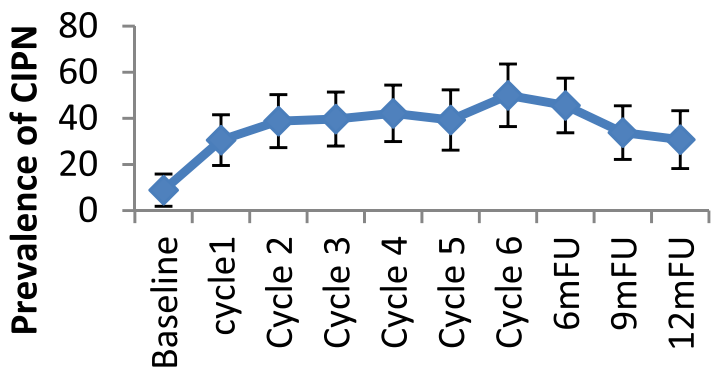

ECIPN-20 Numbness in feet/toes

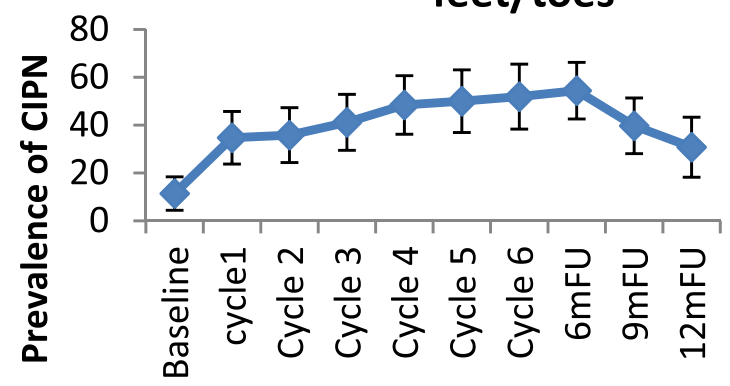

FACTGOG-Ntx Numbness/tingling in hands

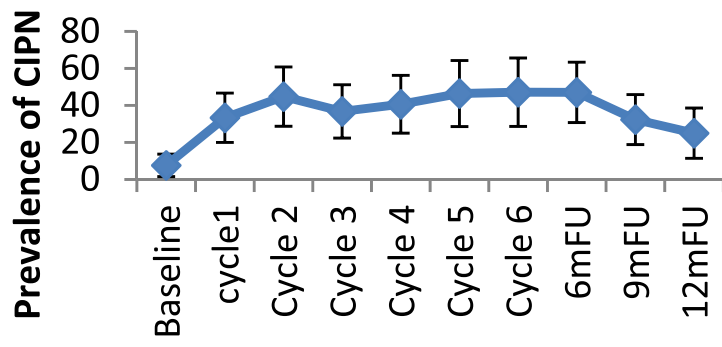

FACTGOG-Ntx Numbness/tingling in feet

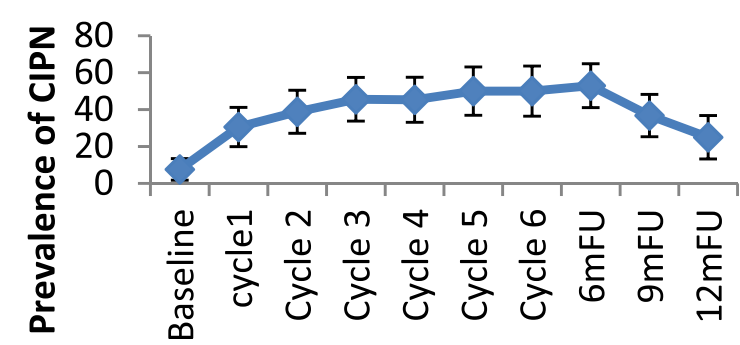

Fig. 4 (Continued) 


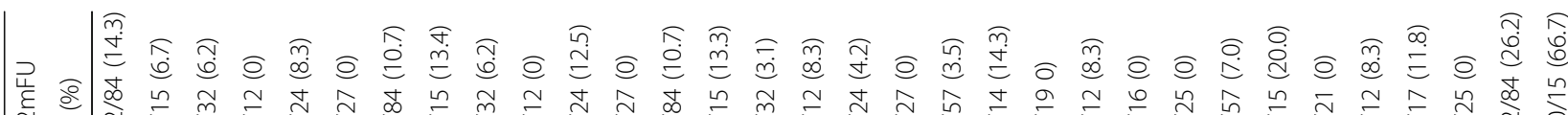

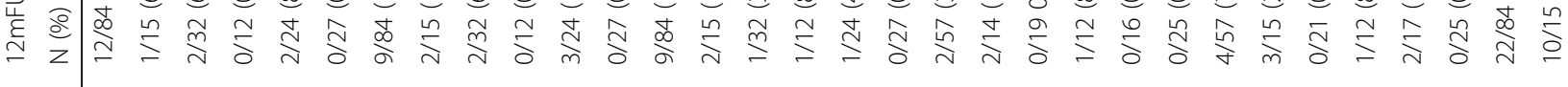

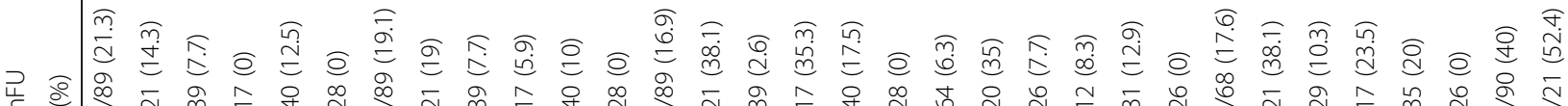

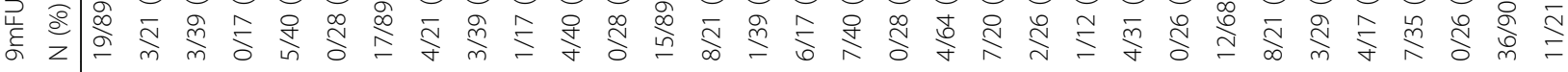

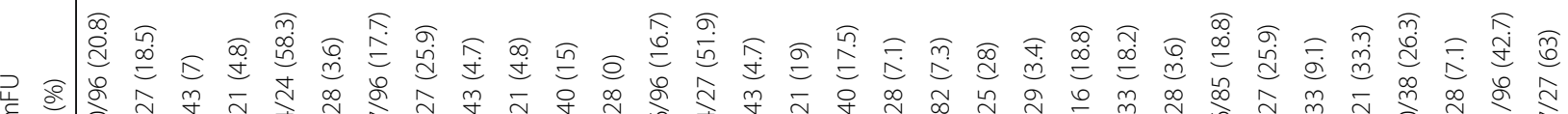

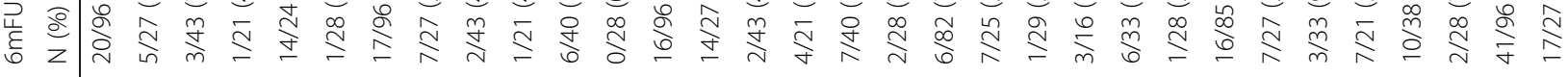

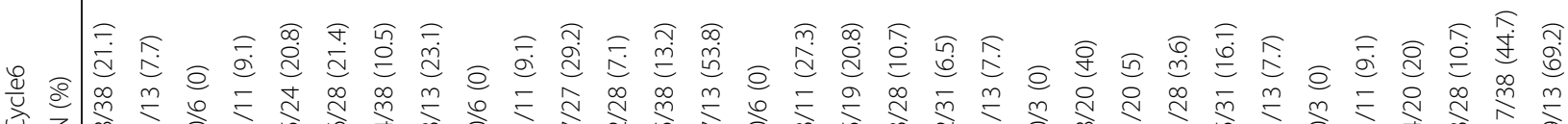

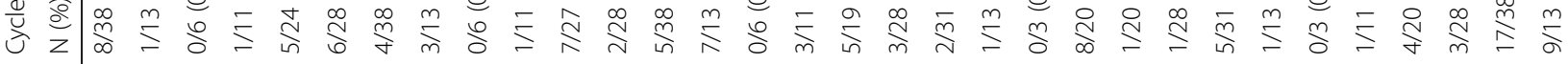

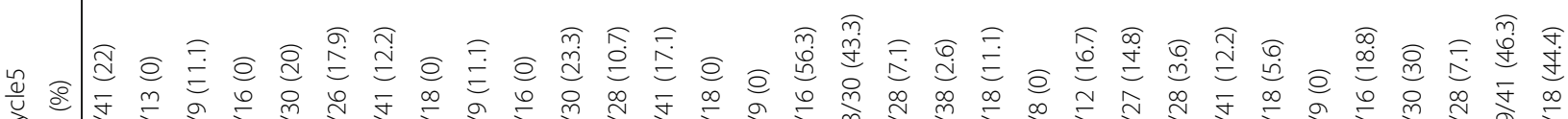

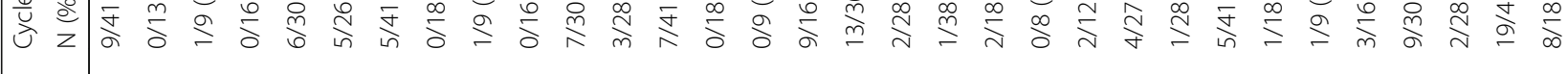

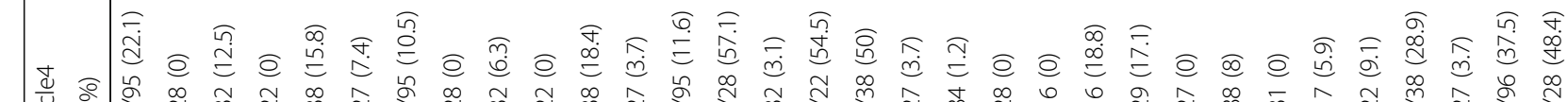

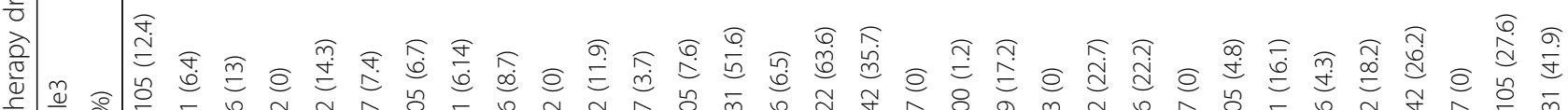
焉

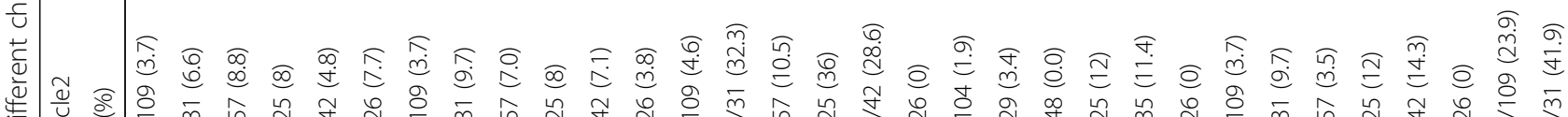

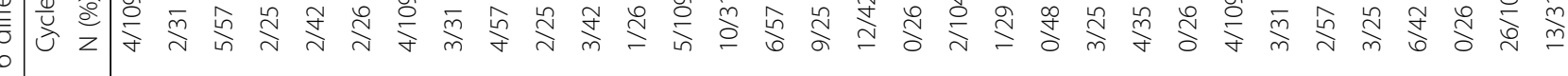

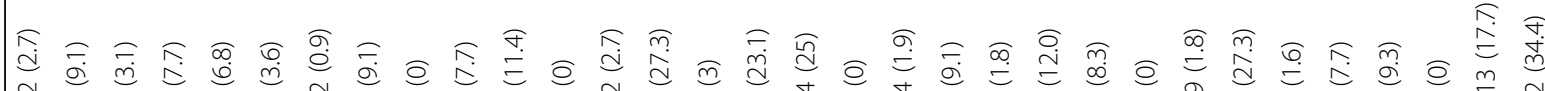

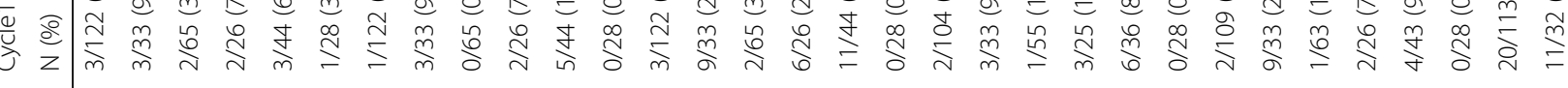

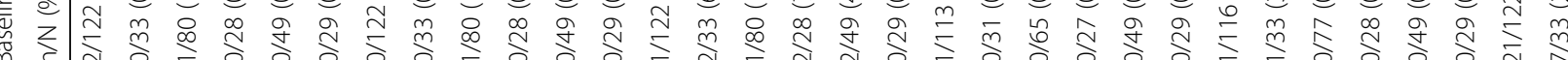




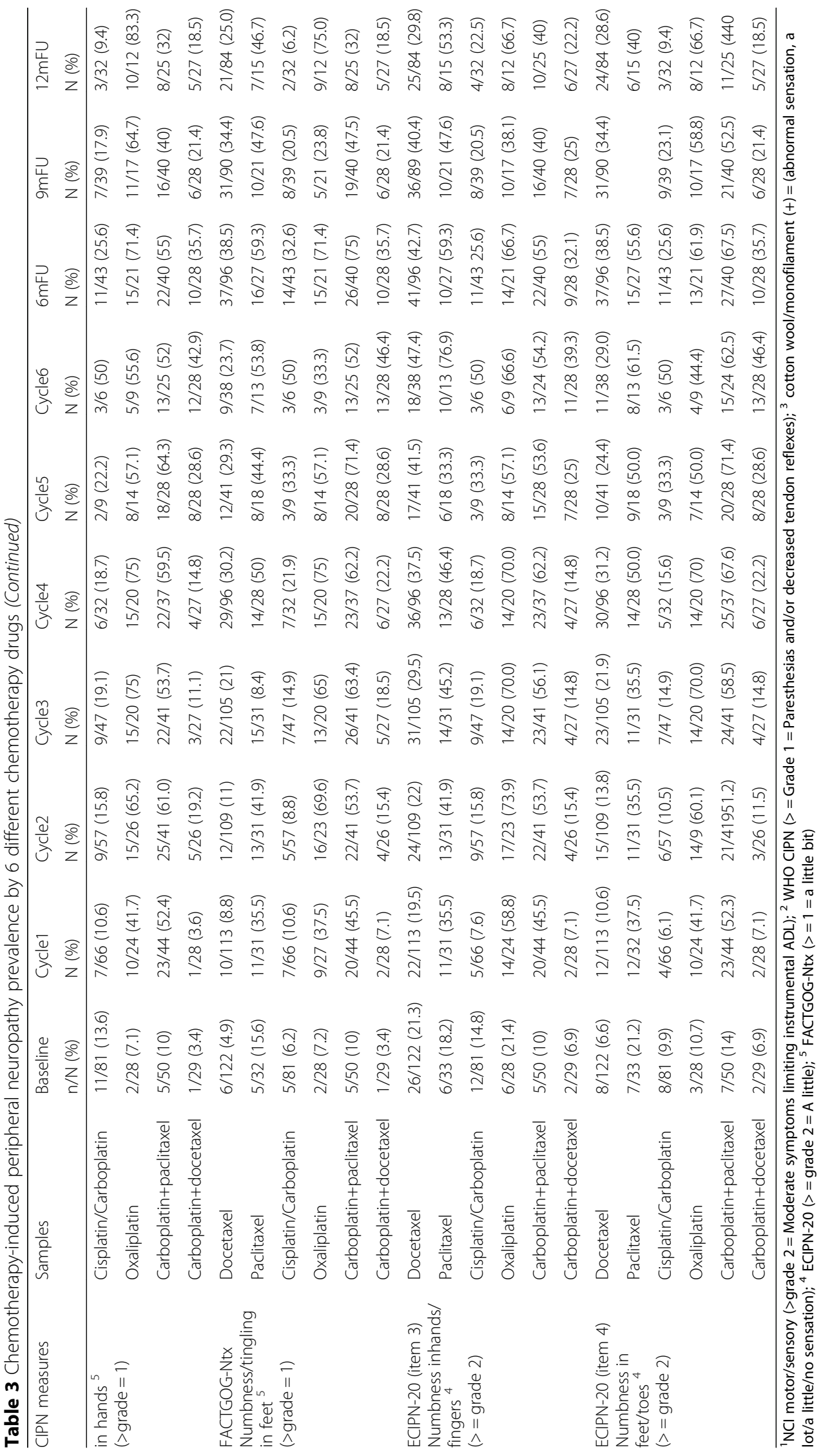


On the other hand, the SNAP velocities had negligible improvement $\left(0.69 \pm 2.78 \%\right.$ lower than $\left.\mathrm{NCS}_{\text {end }}\right)$. The cMAP amplitudes, showed a recovery at $\mathrm{NCS}_{3 \mathrm{~m}}(4.34 \pm 3.05 \%$ higher than $\left.\mathrm{NCS}_{\text {end }}\right)$. The upper limbs did not exhibit much change $\left(0.48 \pm 2.03 \%\right.$ lower than $\left.\mathrm{NCS}_{\text {end }}\right)$, while the lower limbs showed a considerable increase in NCS value $\left(39.41 \pm 16.28 \%\right.$ higher than $\left.\mathrm{NCS}_{\text {end }}\right)$. Similar to the $\mathrm{NCS}_{3 \mathrm{~m}}$ trend of the SNAP amplitudes, the motor velocities suffered a large deterioration $(8.24 \pm 3.91 \%$ lower than $\left.\mathrm{NCS}_{\text {end }}\right)$, with the upper limbs $(6.54 \pm 3.99 \%$ lower than $\left.\mathrm{NCS}_{\text {end }}\right)$ better than the lower limbs $(20.28 \pm 14.07 \%$ compared to lower than $\mathrm{NCS}_{\text {end }}$ ) (Fig. 7).

\section{Discussion}

The current study is the largest and one of a few longitudinal assessments of CIPN (2399 observations) using a heterogeneous population that increases the generalizability of the results. It showed that prevalence was significantly different from measure to measure used, patient reported outcome measures (through quality of life scales) consistently showed much higher CIPN rates than clinician-based or objective measures, and with highest rates in patients receiving taxanes (primarily paclitaxel). Cumulative dose was not linked with higher CIPN prevalence, but time since starting chemotherapy was. Correlations among scales were generally low, although these increased in the later assessments primarily among sensory neuropathy assessments. NCS data confirmed the sensory and motor impairment of participants.

This study confirms that there is wide variation of CIPN prevalence between scales. This is supported by a meta-analysis of CIPN prevalence studies, where confidence intervals were high (i.e. at 3 months CIs $=37-84 \%$ ) [3]. CIPN prevalence is reported in the literature to be high, from 54 to $73 \%$ in some studies [31-33] but often studies are using patient-reported outcome measures to assess prevalence, where CIPN prevalence is not the primary objective. Even in our study, when patient-reported outcome measures were used, prevalence doubled or tripled from that identified by other measures. It remains to be seen if such measures are appropriate diagnostic tools, as they also include items related to autonomic changes; such changes may have pre-existed the chemotherapy and it is unclear if they represent true CIPN-related changes or they are unrelated symptoms, particularly as many of the reporting studies are cross-sectional in nature. In our data, about one-quarter of the patients reported symptoms in the EORTC quality of life CIPN subscales at baseline, before they received any chemotherapy (Table 3). Nevertheless, other studies show similar results with our study including a one-year cumulative prevalence of $28.7 \%$ [34], $23 \%$ in a sample of patients receiving docetaxel [7] and $14.1 \%$ at 1 year [35]. Thus, it is clear that if we focus on prevalence rates that do not derive from patient-reported outcome measures, then prevalence is generally lower to about $15-25 \%$ of patients, the severity is generally not high, and that patient-reported outcome measures may overestimate CIPN prevalence as they include symptoms that may have pre-existed the chemotherapy. If patient-reported outcome measures, which are generally used to assess the 'impact' of a symptom on patients' lives rather than diagnose a condition, are used to show CIPN prevalence, it has to focus more clearly on symptomatology that has developed after the use of chemotherapy, and exclude those that had similar symptoms before the chemotherapy. The latter number we have seen in our study was as high as 21.2\%. Hence, cross-sectional assessments of CIPN using such patient-reported outcome measures can overestimate its prevalence. Irrespective of prevalence rates, however, the impact of the presence of such symptoms is significant $[4,6-10,36]$ and every effort should be made to improve the patient symptom experience.

The issue of reliable and valid measurement of CIPN is fundamental, and based on the (relatively low) correlations between scales shown in this study, it may be that each scale measures a different phenomenon or the scales used in this study were not all sensitive enough to detect CIPN. Which scale from the available ones is best for clinical assessment remains to be identified, and perhaps there is a need for a combination of scales to be used [37]. In our study, the cotton wool assessment led to the lowest 'pick up' rates and at a later time from all other scales suggesting this may not be an appropriate and sensitive enough test. The WHO criterion and the monofilament were highly correlated, suggesting that the former measures more sensory changes. However, the WHO criterion is minimally used in current practice. Abnormalities in vibration and monofilament examinations are associated with abnormal sural nerve amplitudes [38] and hence monofilament may be a useful method in identifying CIPN. The CTCAE is the only scale that assesses separately motor and sensory problems (alongside quality of life scales/ patient-reported outcome measures); while this is an important dimension, in our study the CTCAE identified less patients with CIPN than other scales, suggesting that it may not have high sensitivity. Generally speaking, CIPN is not assessed properly and we should focus more on improving its assessment [6].

A recent review [39] suggests that CIPN is a predominantly sensory symptom with pain; however, in 


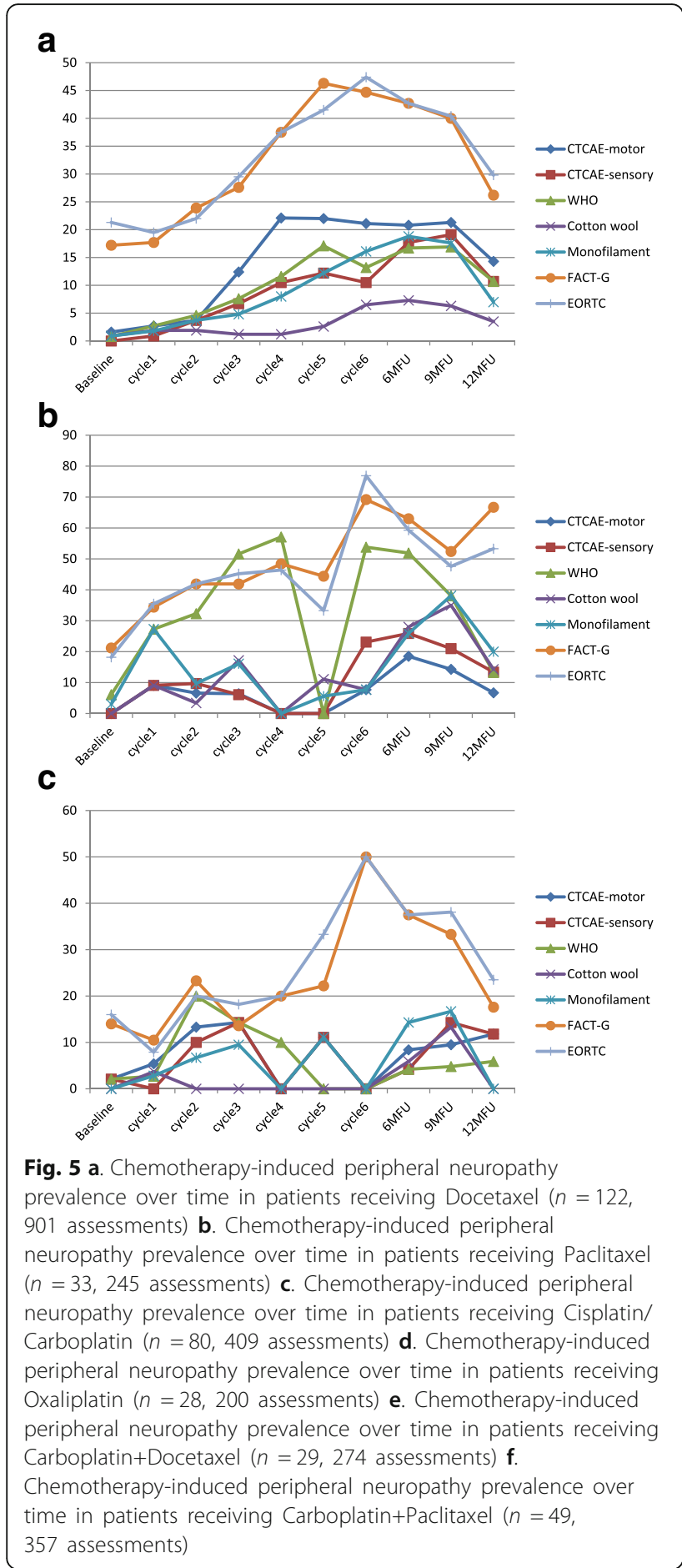

our study we obsered a considerable prevalence of motor neuropathy, particularly in the docetaxel subgroup, across assessments as well as paclitaxel and paclitaxel/carboplatin in the later assessments. This finding should be interpreted with caution as the only motor neuropathy-specific scale we used was the CTCAE item, and the literature suggests that the

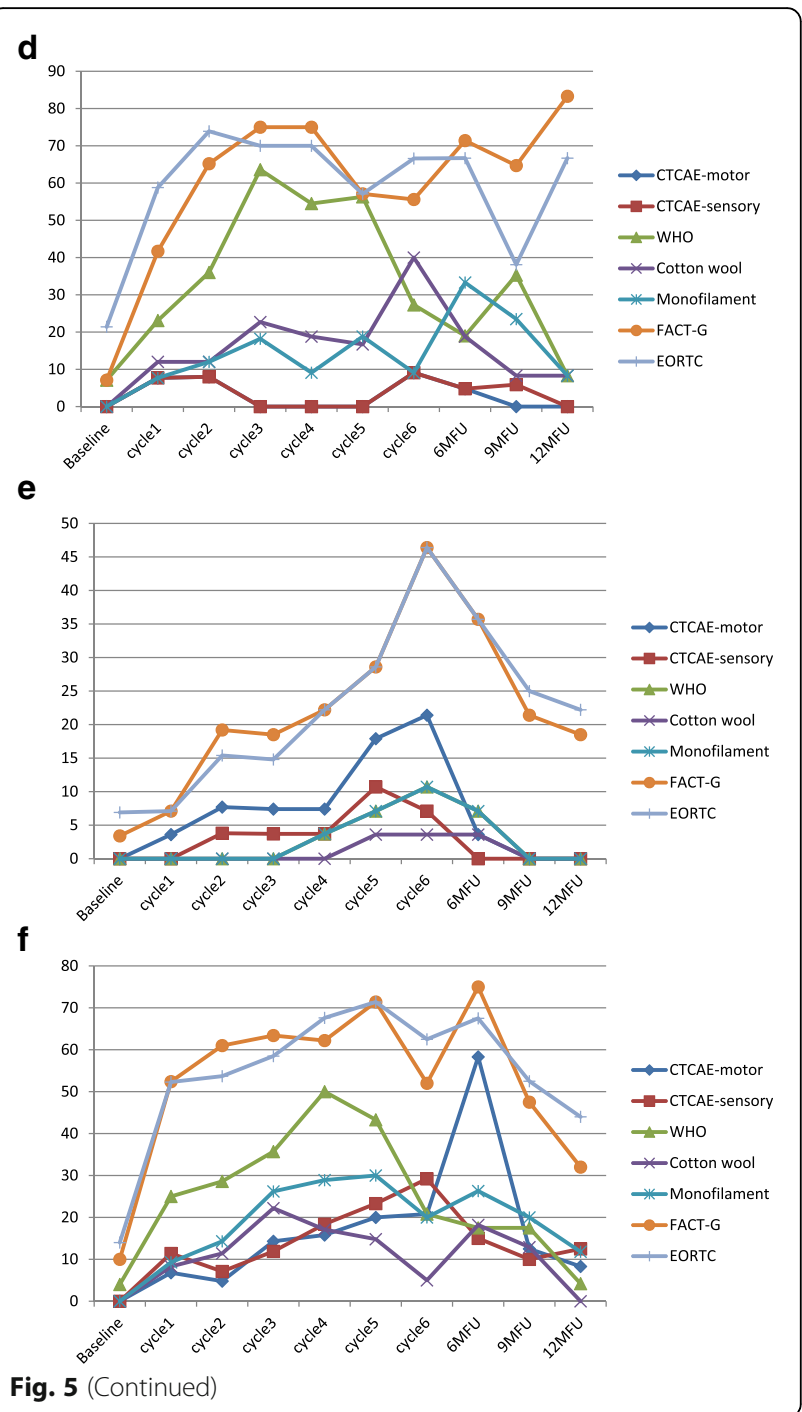

CTACE motor item overestimates its occurrence, possibly as a result of confounding factors [40] although NCS data confirms motor impairment in this sample (suggested by the decreased motor nerve amplitude in our sample). Also, it is unclear whether the motor dysfunction observed is true motor neuropathy or fine motor impairments secondary to sensory loss, which is difficult to distinguish when 'blunt' instruments such as the CTC are used. Motor dysfunction has been shown in a small-scale study, where decreased superexcitability of motor axons was reported [41]. Furthermore, a neurophysiological study in children receiving vincristine showed impaired myotatic reflexes and motor neural impairment [42] and a larger study in oxaliplatin-treated patients found no nerve dysfunction before the initiation of chemotherapy [43] while others studies (ie. ref. [38]) have focused on sensory subclinical changes only. NCS focusing on motor nerves, in addition to sensory nerves, could 

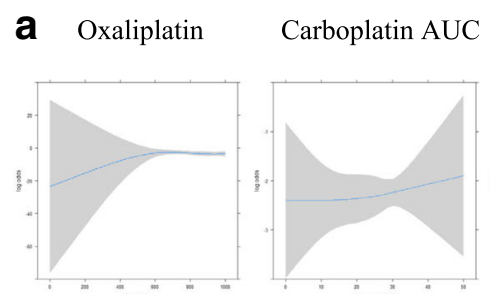

Cisplatin

Paclitaxel

Docetaxel

b Oxaliplatin

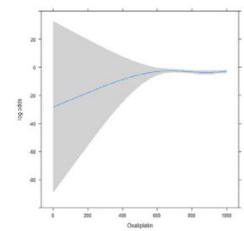

C Oxaliplatin

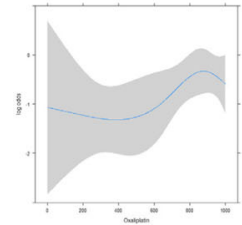

d Oxaliplatin

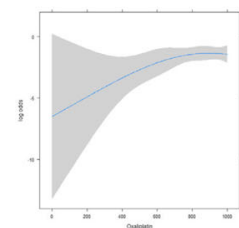

e Oxaliplatin

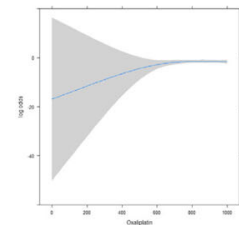

Carboplatin AUC

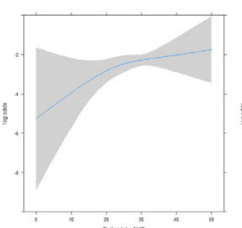

Carboplatin AUC

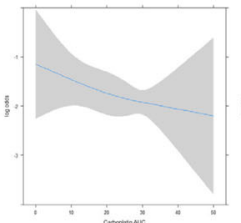

Carboplatin AUC

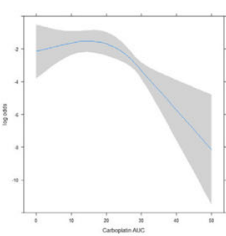

Carboplatin AUC

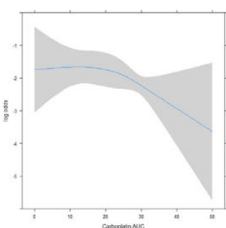

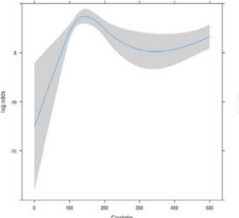
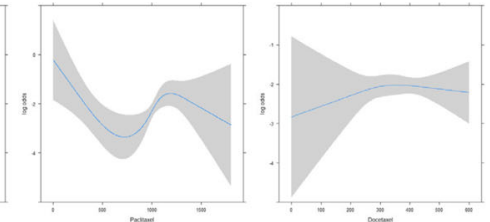

Cisplatin
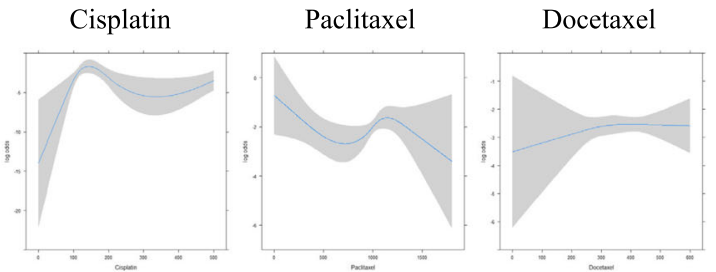

Paclitaxel

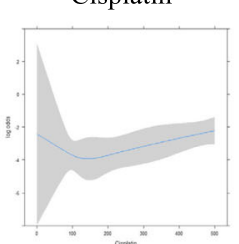

Cisplatin

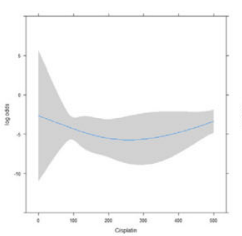

Cisplatin

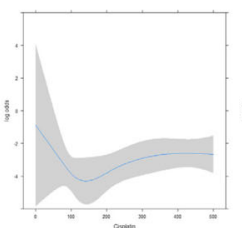

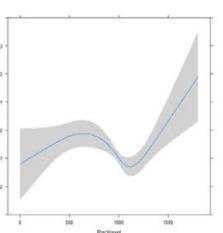

Paclitaxel

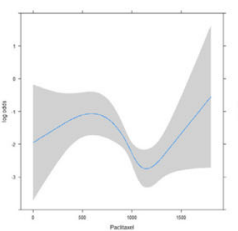

Paclitaxel

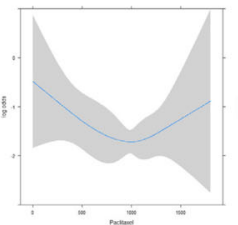

Docetaxel

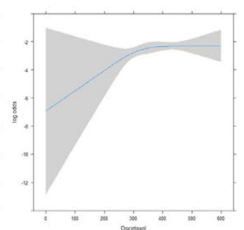

Docetaxel

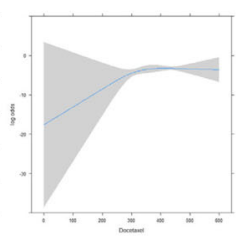

Docetaxel

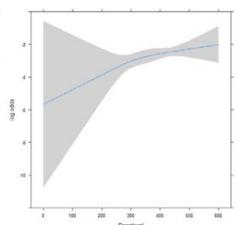

Fig. 6 a. Dose-response relationship related to NCI CTCAE-motor dysfunction scale with oxaliplatin, carboplatin (AUC), cisplatin, paclitaxel and docetaxel respectively $\mathbf{b}$. Dose-response relationship related to NCI CTCAE-sensory dysfunction scale with oxaliplatin, carboplatin (AUC), cisplatin, paclitaxel and docetaxel respectively c. Dose-response relationship related to the WHO neuropathy scale with oxaliplatin, carboplatin (AUC), cisplatin, paclitaxel and docetaxel respectively $6 \mathbf{d}$. Dose-response relationship related to cotton wool assessment with oxaliplatin, carboplatin $(A \cup C)$, cisplatin, paclitaxel and docetaxel respectively e. Dose-response relationship related to monofilament assessment with oxaliplatin, carboplatin (AUC), cisplatin, paclitaxel and docetaxel respectively

highlight if the above comment is correct, and Kandula et al. [44] review the diagnostic role of NCS in CIPN. It may be that there is a general impression that CIPN is mainly sensory impairment as most of the studies in the past assessed sensory problems, with little assessment of motor problems. Motor symptoms may also be hidden under 'fatigue' too, and 'feeling weak' may be interpreted as tired rather than myopathy. Also, it is common in clinical practice to only ask patients if they have any numbness or tingling in the hands/feet, again focusing only on sensory symptoms. There is a need to focus more concretely on the assessment of motor symptoms in the future, as they are also linked with significant impact in daily activities, and define CIPN more broadly as a motor and sensory impairment accompanied by autonomic system manifestations.

Furthermore, pain was not a major issue and occurred in less than one-quarter of the participants, whereas tingling and numbness were most prevalent 
Table 4 Odds ratios of the increased risk of developing neuropathy per 100 mg unit increase (or 1 AUC for carboplatin) of chemotherapy dose (generalized estimating equation)

\begin{tabular}{llllll}
\hline \multirow{2}{*}{ Drug } & Abnormal & & & \\
\cline { 2 - 6 } & NCI CTCAE motor & NCI CTCAE sensory & WHO CIPN & Cotton wool & Monofilament \\
\hline Oxaliplatin-based regimens $(n=27$, observations $=196)$ & $1.15(0.90,1.47)$ & $1.25(0.94,1.67)$ & $1.13(0.95,1.34)$ & $1.32^{*}(1.06,1.64)$ & $1.42^{*}(1.06,1.89)$ \\
Carboplatin AUC (in 1 unit) $(n=88$, observations $=657)$ & $1.03(0.98,1.08)$ & $1.06^{*}(1.01,1.10)$ & $0.98(0.93,1.03)$ & $0.93^{*}(0.88,0.99)$ & $0.96(0.92,1.01)$ \\
Cisplatin-based regimens $(n=70$, observations $=362)$ & $0.89(0.55,1.46)$ & $0.90(0.55,1.49)$ & $1.43(0.94,2.19)$ & $1.28(0.57,2.91)$ & $1.37(0.86,2.17)$ \\
Paclitaxel-based regimens $(n=83$, observations $=621)$ & $1.02(0.83,1.25)$ & $1.01(0.85,1.20)$ & $1.01(0.92,1.11)$ & $0.91(0.80,1.04)$ & $0.94(0.84,1.06)$ \\
Docetaxel-based regimens $(n=151$, observations $=1167)$ & $0.96(0.69,1.32)$ & $1.03(0.69,1.52)$ & $1.36(0.91,2.04)$ & $2.12(0.93,4.81)$ & $1.47(0.96,2.25)$ \\
\hline
\end{tabular}

*Significant at $5 \%$ level

in more than half the sample. Pain may be more prevalent in oxaliplatin $[45,46]$ or paclitaxel-based chemotherapy but it seems to be less common in other taxane- or platinum-based chemotherapies [47]. Whether autonomic symptoms are the result of CIPN or symptoms reflecting other pre-existing conditions before chemotherapy treatment is not clear as yet, and more prospective work needs to be done in this area too. Also, many other symptoms were reported by patients at different degrees in each type of chemotherapy suggesting that CIPN is not the same symptom across taxanes and platins. This is an important finding to consider particularly when we assess patients or when therapeutic trials for CIPN (in terms of primary outcome) are planned.

At the 12-month assessment, a significant number (around 8\% through objective and physician-based scales or $25-30 \%$ based on the patient-reported outcome measure) remained with CIPN symptoms, similar or somewhat lower to other studies in the past [7,
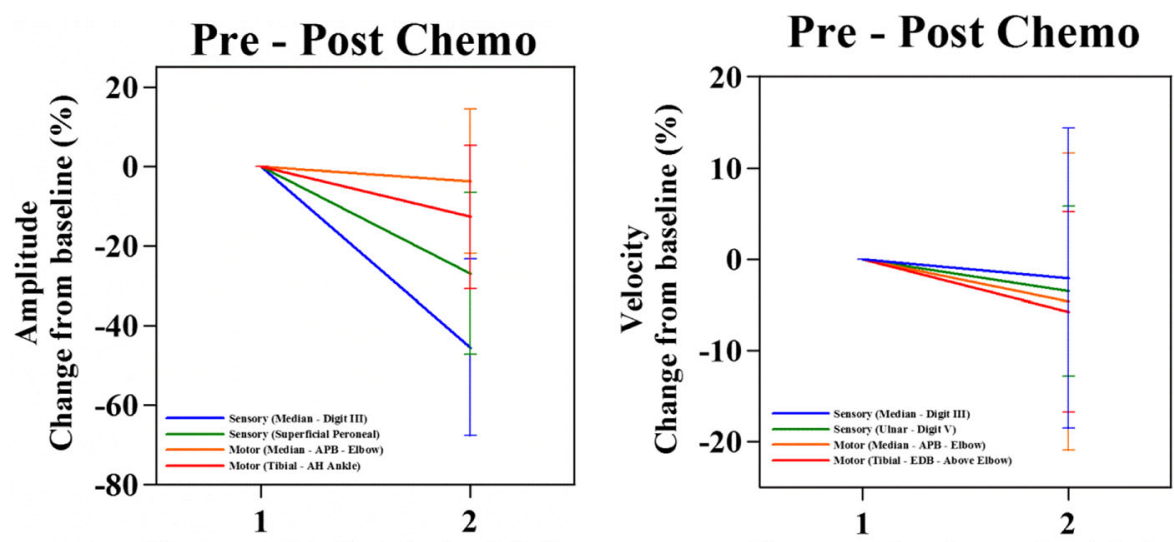

Nerve conduction study visit \#

Nerve conduction study visit \#
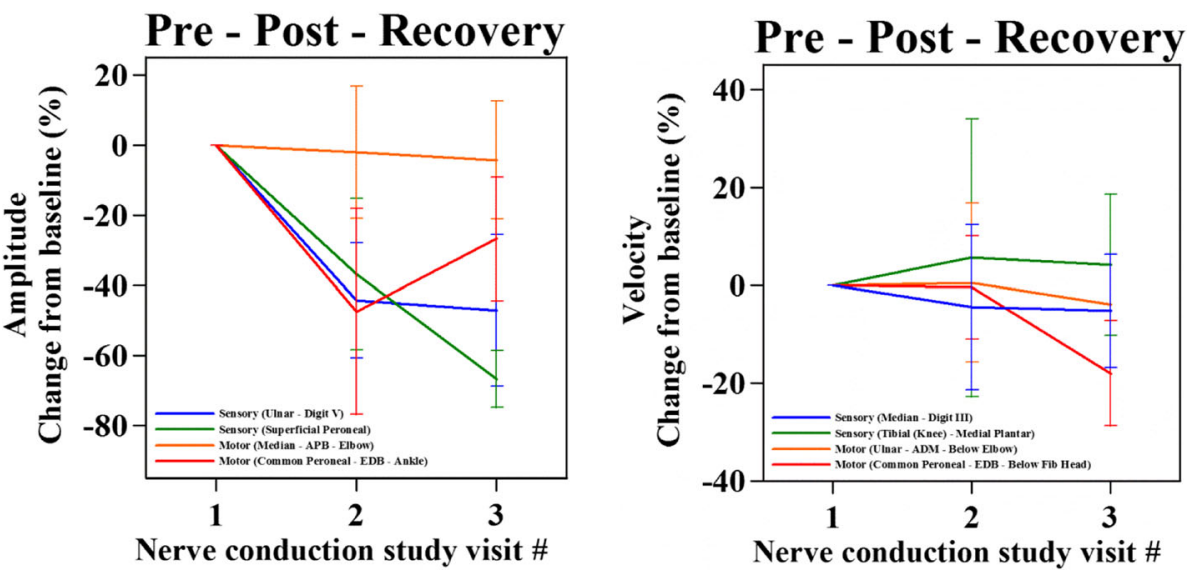

Fig. 7 Changes observed in chemotherapy-induced peripheral neuropathy through Nerve Conduction Studies. The graph values correspond to the average of percentage differences to baseline (pre-NCS) of post-NCS and recovery-NCS 
34, 35, 48]. As CIPN has been seen in patients even 11-12 years after chemotherapy [10, 49], it seems that this group of patients may experience chronic and long-lasting CIPN.

Cumulative dose of the chemotherapy was not a predictive factor for CIPN, against the currently held belief, in any of the chemotherapy regimens we assessed. An increasing body of literature shows similar results $[31,50]$. This brings into question the current practice $[51,52]$ of dose reductions or chemotherapy discontinuation in patients experiencing CIPN. This finding, alongside with the key factor of time since chemotherapy, suggests that from the moment CIPN is experienced, it will continue to increase for the next few months and carry its course before we see any noticeable decreases after 6 months, irrespective of dose of chemotherapy [53], and patients may continue developing CIPN over time even if doses are reduced [54]. Whether treatment discontinuation or dose reductions have a real impact on decreasing CIPN should be assessed in future research.

Limitations of the study include the decrease in the sample over cycles (many patients did not complete more than 3-4 cycles or were ill/dead, giving significant missing data particularly in the 5th-6th cycle data. Some chemotherapy protocols also had a relatively small sample size. Where numbers were small, results should be interpreted with caution. Interrater reliability of the assessments may be an issue, although specific training and a protocol guide was provided to all assessors. The sample from Caucasians was also small compared to the Chinese and other Asian sample included. Some of the assessments used (i.e. WHO criterion; cotton wool) have not been rigorously evaluated as assessment methods in the CIPN context) and hence interpretation of results from these scales should be cautious. Cotton wool test and $10 \mathrm{~g}$ monofilament can detect sensory impairment, but they are unable to capture deep sensory impairment. This is typical of platinum drugs neuropathy and might partly explain why they are performing less efficiently than tuning fork examination in comparison with literature data.

\section{Conclusions}

This study maps the development and progression of CIPN in patients receiving taxane- and platinum-based chemotherapy, showing distinct CIPN profiles. It shows a lower level of CIPN than previously reported with significant differences among different chemotherapy protocols and scales used to measure CIPN. It brings into question the sensitivity and/or appropriateness of scales currently used to measure CIPN. Nevertheless, CIPN is a clinical problem present even 1 year after treatments and needs careful clinical attention. Practice-important findings include that early CIPN predicts CIPN in subsequent cycles, and this is the case irrespective of cumulative dose of chemotherapy. More work is needed in ascertaining best assessment methods for clinical practice and the findings call for a re-think of current clinical practices.

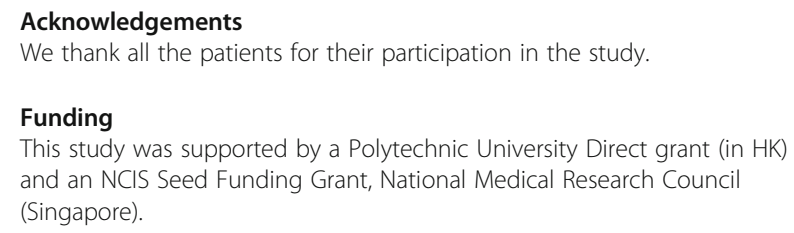

\section{Funding}

This study was supported by a Polytechnic University Direct grant (in HK) and an NCIS Seed Funding Grant, National Medical Research Council (Singapore).

\section{Availability of data and materials}

The datasets used and/or analysed during the current study are available from the corresponding author on reasonable request.

\section{Authors' contributions}

Conception of the study: AM, LKPS. Development of study protocol: AM, VL, JSKA, KTL, YCL, KHW, RS. Participant recruitment: HLC, JSKA, KTL, YCL, KHW, CF, RS. Participant follow-up and assessment: HLC, VL, AC, CWC, JY, CF, RS. Nerve Conduction Studies: AC, AB, RS. Data analysis: AM, HLC, VL, AC, AB, RS. Contribution to writing the paper including discussion: all. All authors read and approved the final manuscript.

\section{Ethics approval and consent to participate}

The study has been approved by the ethics committees of the Hong Kong Polytechnic University, Hong Kong; Central Cluster of the Hospital Authority, Hong Kong; The National University Hospital; Singapore; The University of Manchester, Manchester, UK; and the Central Manchester Research and Ethics Committee. All participants have provided written informed consent.

\section{Consent for publication}

Not applicable.

\section{Competing interests}

The authors declare that they have no competing interests.

\section{Publisher's Note}

Springer Nature remains neutral with regard to jurisdictional claims in published maps and institutional affiliations.

\section{Author details \\ ${ }^{1}$ School of Nursing, The Hong Kong Polytechnic University, Hong Kong, Hong Kong, Special Administrative Region of China. ${ }^{2}$ Alice Lee Centre for Nursing Studies, National University of Singapore, Singapore, Singapore. ${ }^{3}$ The Hong Kong Adventist Hospital, Hong Kong, Hong Kong, Special \\ Administrative Region of China. ${ }^{4}$ Department of Pharmacy, National University of Singapore, Singapore, Singapore. ${ }^{5}$ Singapore Institute for Neurotechnology (SINAPSE), National University of Singapore, Singapore, Singapore. ${ }^{6}$ Department of Clinical Oncology, Queen Elisabeth Hospital, Hong Kong, Hong Kong, Special Administrative Region of China. ${ }^{7}$ Division of Nursing, Midwifery \& Social Work, University of Manchester, UK and Christie NHS Foundation Trust, Manchester, UK. ${ }^{8}$ Department of \\ Haematology-Oncology, National University Health System, Singapore, Singapore.}

Received: 15 April 2018 Accepted: 14 January 2019

Published online: 08 February 2019

\section{References}

1. Hausheer FH, Schilsky RL, Bain S, Berghorn EJ, Lieberman F. Diagnosis, management, and evaluation of chemotherapy-induced peripheral neuropathy. Semin Oncol. 2006;33:15-49.

2. Postma TJ, Heimans JJ. Grading of chemotherapy-induced peripheral neuropathy. Ann Oncol. 2000;11:509-13.

3. Seretny M, Currie GL, Sena ES, Ramnarine S, Grant R, MacLeod MR, Colvin LA, Fallon M. Incidence, prevalence, and predictors of chemotherapy- 
induced peripheral neuropathy: a systematic review and meta-analysis. Pain. 2014;155(12):2461-70.

4. Mols F, Beijers T, Vreugdenhil G, van de Poll-Franse L. Chemotherapy-induced peripheral neuropathy and its association with quality of life: a systematic review. Support Care Cancer. 2014; 22(8):2261-9

5. Miaskowski C, Mastick J, Paul SM, Topp K, Smoot B, Abrams G, Chen LM, Kober KM, Conley YP, Chesney M, Bolla K, Mausisa G, Mazor M, Wong M, Schumacher M, Levine JD. Chemotherapy-induced neuropathy in Cancer survivors. J Pain Symptom Manag. 2017;54(2):204-18.

6. Cavaletti G, Frigeni B, Lanzani F, Mattavelli L, Susani E, Alberti P, Cortinovis D, Bidoli P. Chemotherapy-induced peripheral neurotoxicity assessment: a critical revision of the currently available tools. Eur J Cancer. 2010;46(3):479-94.

7. Eckhoff $L$, Knoop A, Jensen MB, Ewertz M. Persistence of docetaxel-induced neuropathy and impact on quality of life among breast cancer survivors. Eur J Cancer. 2015;51(3):292-300.

8. Shimozuma K, Ohashi Y, Takeuchi A, Aranishi T, Morita S, Kuroi K, Ohsumi S, Makino H, Katsumata N, Kuranami M, Suemasu K, Watanabe T, Hausheer FH. Taxane-induced peripheral neuropathy and health-related quality of life in postoperative breast cancer patients undergoing adjuvant chemotherapy: N-SAS BC 02, a randomized clinical trial. Support Care Cancer. 2012;20(12): 3355-64.

9. Gewandter JS, Fan L, Magnuson A, Mustian K, Peppone L, Heckler C, Hopkins J, Tejani M, Morrow GR, Mohile SG. Falls and functional impairments in cancer survivors with chemotherapy-induced peripheral neuropathy (CIPN): a University of Rochester CCOP study. Support Care Cancer. 2013;21(7):2059-66.

10. Ezendam NP, Pijlman B, Bhugwandass C, Pruijt JF, Mols F, Vos MC, Pijnenborg JM, Van de Poll-Franse LV. Chemotherapy-induced peripheral neuropathy and its impact on health-related quality of life among ovarian cancer survivors: results from the population-based PROFILES registry. Gynecol Oncol. 2014;135(3):510-7.

11. Zanville NR, Nudelman KN, Smith DJ, Von Ah D, McDonald BC, Champion VL, Saykin AJ. Evaluating the impact of chemotherapy-induced peripheral neuropathy symptoms (CIPN-sx) on perceived ability to work in breast cancer survivors during the first year post-treatment. Support Care Cancer. 2016;24(11):4779-89.

12. Pike $C T$, Birnbaum $H G$, Muehlenbein $C E$, Pohl GM, Natale RB. Healthcare costs and workloss burden of patients with chemotherapy-associated peripheral neuropathy in breast, ovarian, head and neck, and nonsmall cell lung cancer. Chemother Res Pract. 2012;2012:913848.

13. McCrary JM, Goldstein D, Boyle F, Cox K, Grimison P, Kiernan MC, Krishnan AV, Lewis CR, Webber K, Baron-Hay S, Horvath L, Park SB, IN FOCUS Delphi working party. Optimal clinical assessment strategies for chemotherapy-induced peripheral neuropathy (CIPN): a systematic review and Delphi survey. Support Care Cancer. 2017;25(11):3485-93.

14. Frigeni B, Piatti M, Lanzani F, Alberti P, Villa P, Zanna C, Ceracchi M, Ildebrando M, Cavaletti G. Chemotherapy-induced peripheral neurotoxicity can be misdiagnosed by the National Cancer Institute common toxicity scale. J Peripher Nerv Syst. 2011;16(3):228-36.

15. Cavaletti G, Cornblath DR, Merkies IS, Postma TJ, Rossi E, Frigeni B, Alberti P, Bruna J, Velasco R, Argyriou AA, Kalofonos HP, Psimaras D, Ricard D, Pace A, Galiè E, Briani C, Dalla Torre C, Faber CG, Lalisang Rl, Boogerd W, Brandsma D, Koeppen S, Hense J, Storey D, Kerrigan S, Schenone A, Fabbri S, Valsecchi MG, Cl-PeriNomS Group. The chemotherapy-induced peripheral neuropathy outcome measures standardization study: from consensus to the first validity and reliability findings. Ann Oncol. 2013;24(2):454-62.

16. Haryani H, Fetzer SJ, Wu CL, Hsu YY. Chemotherapy-induced peripheral neuropathy assessment tools: a systematic review. Oncol Nurs Forum. 2017; 44(3):E111-23.

17. Cleeland CS, Farrar JT, Hausheer FH. Assessment of Cancer-related neuropathy and neuropathic pain. Oncologist. 2010;15(suppl 2):13-8.

18. Kuroi K, Shimozuma K, Ohashi Y, Takeuchi A, Aranishi T, Morita S, Ohsumi $S$, Watanabe T, Bain S, Hausheer FH. A questionnaire survey of physicians' perspectives regarding the assessment of chemotherapy-induced peripheral neuropathy in patients with breast cancer. Jpn J Clin Oncol. 2008;38(11): $748-54$.

19. Shimozuma K, Ohashi Y, Takeuchi A, Aranishi T, Morita S, Kuroi K, Ohsumi S, Makino H, Mukai F, Katsumata N, Sunada Y, Watanabe T, Hausheer FH. Feasibility and validity of the patient neurotoxicity questionnaire (PNQ) during taxane chemotherapy in a phase III randomized trial in patients with breast cancer: N-SAS BC 02. Support Care Cancer. 2009;17(12):1483-91.

20. Kuroi K, Shimozuma K, Ohashi Y, Hisamatsu K, Masuda N, Takeuchi A, Aranishi T, Morita S, Ohsumi S, Hausheer FH. Prospective assessment of chemotherapy-induced peripheral neuropathy due to weekly paclitaxel in patients with advanced or metastatic breast cancer (CSPHOR 02 study). Support Care Cancer. 2009;17(8):1071-80.

21. Le-Rademacher J, Kanwar R, Seisler D, Pachman DR, Qin R, Abyzov A, Ruddy KJ, Banck MS, Lavoie Smith EM, Dorsey SG, Aaronson NK, Sloan J, Loprinzi CL, Beutler AS. Patient-reported (EORTC QLQCIPN20) versus physician-reported (CTCAE) quantification of oxaliplatin- and paclitaxel/carboplatin-induced peripheral neuropathy in NCCTG/Alliance clinical trials. Support Care Cancer. 2017;25(11): 3537-44.

22. Cavaletti G, Frigeni B, Lanzani F, Piatti M, Rota S, Briani C, Zara G, Plasmati R, Pastorelli F, Caraceni A, Pace A, Manicone M, Lissoni A, Colombo N, Bianchi G, Zanna C, Italian NETox group. The Total neuropathy score as an assessment tool for grading the course of chemotherapy-induced peripheral neurotoxicity: comparison with the National Cancer Institutecommon toxicity scale. J Peripher Nerv Syst. 2007;12(3):210-5.

23. Rivera DR, Ganz PA, Weyrich MS, Bandos H, Melnikow J. Chemotherapyassociated peripheral neuropathy in patients with early-stage breast Cancer: a systematic review. J Natl Cancer Inst, 110 2018, djx140, https://doi.org/10. 1093/jnci/djx140

24. WHO. Handbook for reporting results of Cancer treatment. WHO offset publication no. 48. Geneva: World Health Organization; 1979.

25. Dros J, Wewerinke A, Bindels PJ, van Weert HC. Accuracy of monofilament testing to diagnose peripheral neuropathy: a systematic review. Ann Fam Med. 2009; 7(6):555-8.

26. Calhoun EA, Welshman EE, Chang CH, Lurain JR, Fishman DA, Hunt TL, Cella D. Psychometric evaluation of the functional assessment of Cancer therapy/ gynecologic oncology group-neurotoxicity (Fact/GOG-Ntx) questionnaire for patients receiving systemic chemotherapy. Int J Gynecol Cancer. 2003;13: $741-8$.

27. Huang HQ, Brady MF, Cella D, Fleming G. Validation and reduction of FACT/ GOG-Ntx subscale for platinum/paclitaxel-induced neurologic symptoms: a gynecologic oncology group study. Int J Gynecol Cancer. 2007;17:387-93.

28. Postma TJ, Aaronson NK, Heimans JJ, Muller MJ, Hildebrand JG, Delattre JY, Hoang-Xuan K, Lantéri-Minet M, Grant R, Huddart R, Moynihan C, Maher J, Lucey R, EORTC quality of life group. The development of an EORTC quality of life questionnaire to assess chemotherapy-induced peripheral neuropathy: the QLQ-CIPN20. Eur J Cancer. 2005;41(8):1135-9.

29. Karandreas N, Papatheodorou A, Triantaphilos I, Mavridis M, Lygidakis C. Sensory nerve conduction studies of the less frequently examined nerves. Electromyogr Clin Neurophysiol. 1995;35:169-73.

30. Ping Ng KW, Ong JJ, Nyein Nyein TD, Liang S, Chan YC, Lee KO, WilderSmith EP. EMLA-induced skin wrinkling for the detection of diabetic neuropathy. Front Neurol. 2013;4:126.

31. Simon NB, Danso MA, Alberico TA, Basch E, Bennett AV. The prevalence and pattern of chemotherapy-induced peripheral neuropathy among women with breast cancer receiving care in a large community oncology practice. Qual Life Res. 2017;26(10):2763-72.

32. Bao T, Basal C, Seluzicki C, Li SQ, Seidman AD, Mao JJ. Long-term chemotherapy-induced peripheral neuropathy among breast cancer survivors: prevalence, risk factors, and fall risk. Breast Cancer Res Treat. 2016; 159(2):327-33.

33. Goldstein D, Von Hoff DD, Moore M, Greeno E, Tortora G, Ramanathan RK, Macarulla T, Liu H, Pilot R, Ferrara S, Lu B. Development of peripheral neuropathy and its association with survival during treatment with nabpaclitaxel plus gemcitabine for patients with metastatic adenocarcinoma of the pancreas: a subset analysis from a randomised phase III trial (MPACT). Eur J Cancer. 2016;52:85-91.

34. Pereira S, Fontes F, Sonin T, Dias T, Fragoso M, Castro-Lopes JM, Lunet N. Chemotherapy-induced peripheral neuropathy after neoadjuvant or adjuvant treatment of breast cancer: a prospective cohort study. Support Care Cancer. 2016;24(4):1571-81.

35. Fontes F, Pereira S, Castro-Lopes JM, Lunet N. A prospective study on the neurological complications of breast cancer and its treatment: updated analysis three years after cancer diagnosis. Breast. 2016;29:31-8.

36. Speck RM, DeMichele A, Farrar JT, Hennessy S, Mao JJ, Stineman MG, Barg FK. Scope of symptoms and self-management strategies for chemotherapy- 
induced peripheral neuropathy in breast cancer patients. Support Care Cancer. 2012;20(10):2433-9.

37. Alberti P, Rossi E, Cornblath DR, Merkies IS, Postma TJ, Frigeni B, Bruna J, Velasco R, Argyriou AA, Kalofonos HP, Psimaras D, Ricard D, Pace A, Galiè E, Briani C, Dalla Torre C, Faber CG, Lalisang Rl, Boogerd W, Brandsma D, Koeppen S, Hense J, Storey D, Kerrigan S, Schenone A, Fabbri S, Valsecchi MG, Cavaletti G, Cl-PeriNomS Group. Physician-assessed and patientreported outcome measures in chemotherapy-induced sensory peripheral neurotoxicity: two sides of the same coin. Ann Oncol. 2014;25(1):257-64.

38. Griffith KA, Dorsey SG, Renn CL, Zhu S, Johantgen ME, Cornblath DR, Argyriou AA, Cavaletti G, Merkies IS, Alberti P, Postma TJ, Rossi E, Frigeni B, Bruna J, Velasco R, Kalofonos HP, Psimaras D, Ricard D, Pace A, Galie E, Briani C, Dalla Torre C, Faber CG, Lalisang Rl, Boogerd W, Brandsma D, Koeppen S, Hense J, Storey DJ, Kerrigan S, Schenone A, Fabbri S, Valsecchi MG, ClPeriNomS Group. Correspondence between neurophysiological and clinical measurements of chemotherapy-induced peripheral neuropathy: secondary analysis of data from the Cl-PeriNomS study. J Peripher Nerv Syst. 2014; 19(2):127-35.

39. Staff NP, Grisold A, Grisold W, Windebank AJ. Chemotherapy-induced peripheral neuropathy: a current review. Ann Neurol. 2017;81(6):772-81.

40. Frigeni B, Piatti M, Lanzani F, Alberti P, Villa P, Zanna C, Ceracchi M, Ildebrando M, Cavaletti G. Chemotherapy-induced peripheral neurotoxicity can be misdiagnosed by the National Cancer Institute common toxicity scale. J Peripher Nerv Syst. 2011;6(3):228-36.

41. Heide R, Bostock H, Ventzel L, Grafe P, Bergmans J, Fuglsang-Frederiksen A, Finnerup NB, Tankisi $\mathrm{H}$. Axonal excitability changes and acute symptoms of oxaliplatin treatment: in vivo evidence for slowed sodium channel inactivation. Clin Neurophysiol. 2018;129(3):694-706.

42. Kavcic M, Koritnik B, Krzan M, Velikonja O, Prelog T, Stefanovic M, Debeljak M, Jazbec J. Electrophysiological studies to detect peripheral neuropathy in children treated with vincristine. J Pediatr Hematol Oncol. 2017;39(4):266-71.

43. Kandula T, Farrar MA, Krishnan AV, Murray J, Timmins HC, Goldstein D, Lin CS, Kiernan MC, Park SB. Multimodal quantitative examination of nerve function in colorectal cancer patients prior to chemotherapy. Muscle Nerve. 2018:57(4):615-21.

44. Kandula T, Farrar MA, Kiernan MC, Krishnan AV, Goldstein D, Horvath L, Grimison P, Boyle F, Baron-Hay S, Park SB. Neurophysiological and clinical outcomes in chemotherapy-induced neuropathy in cancer. Clin Neurophysiol. 2017;128(7):1166-75.

45. Ventzel $L$, Jensen $A B$, Jensen AR, Jensen TS, Finnerup NB. Chemotherapyinduced pain and neuropathy: a prospective study in patients treated with adjuvant oxaliplatin or docetaxel. Pain. 2016;157(3):560-8.

46. Attal $N$, Bouhassira $D$, Gautron $M$, Vaillant $J N$, Mitry $E$, Lepère $C$, Rougier $P$, Guirimand F. Thermal hyperalgesia as a marker of oxaliplatin neurotoxicity: a prospective quantified sensory assessment study. Pain. 2009;144(3):245-52.

47. Wolf SL, Barton DL, Qin R, Wos EJ, Sloan JA, Liu H, Aaronson NK, Satele DV Mattar BI, Green NB, Loprinzi CL. The relationship between numbness, tingling, and shooting/burning pain in patients with chemotherapy-induced peripheral neuropathy (CIPN) as measured by the EORTC QLQ-CIPN20 instrument, N06CA. Support Care Cancer. 2012;20(3):625-32.

48. Hershman DL, Till C, Wright JD, Awad D, Ramsey SD, Barlow WE, Minasian LM, Unger J. Comorbidities and risk of chemotherapy-induced peripheral neuropathy among participants 65 years or older in southwest oncology group clinical trials. J Clin Oncol. 2016;34(25):3014-22.

49. Mols F, Beijers T, Lemmens V, van den Hurk CJ, Vreugdenhil G, Van de PollFranse LV. Chemotherapy-induced neuropathy and its association with quality of life among 2- to 11-year colorectal cancer survivors: results from the population-based PROFILES registry. J Clin Oncol. 2013;31(21):2699-707.

50. Brouwers EE, Huitema AD, Boogerd W, Beijnen JH, Schellens JH. Persistent neuropathy after treatment with cisplatin and oxaliplatin. Acta Oncol. 2009; 48(6):832-41.

51. Eckhoff L, Knoop AS, Jensen MB, Ejlertsen B, Ewertz M. Risk of docetaxelinduced peripheral neuropathy among 1,725 Danish patients with early stage breast cancer. Breast Cancer Res Treat. 2013;142(1):109-18.

52. Bhatnagar B, Gilmore S, Goloubeva O, Pelser C, Medeiros M, Chumsri S, Tkaczuk K, Edelman M, Bao T. Chemotherapy dose reduction due to chemotherapy induced peripheral neuropathy in breast cancer patients receiving chemotherapy in the neoadjuvant or adjuvant settings: a singlecenter experience. Springerplus. 2014;3:366. https://doi.org/10.1186/21931801-3-366.
53. Pachman DR, Qin R, Seisler D, Smith EM, Kaggal S, Novotny P, Ruddy KJ Lafky JM, Ta LE, Beutler AS, Wagner-Johnston ND, Staff NP, Grothey A, Dougherty PM, Cavaletti G, Loprinzi CL. Comparison of oxaliplatin and paclitaxel-induced neuropathy (Alliance A151505). Support Care Cancer. 2016;24(12):5059-68.

54. Beijers AJ, Mols F, Tjan-Heijnen VC, Faber CG, van de Poll-Franse LV, Vreugdenhil G. Peripheral neuropathy in colorectal cancer survivors: the influence of oxaliplatin administration. Results from the population-based PROFILES registry. Acta Oncol. 2015;54(4):463-9.

\section{Ready to submit your research? Choose BMC and benefit from:}

- fast, convenient online submission

- thorough peer review by experienced researchers in your field

- rapid publication on acceptance

- support for research data, including large and complex data types

- gold Open Access which fosters wider collaboration and increased citations

- maximum visibility for your research: over $100 \mathrm{M}$ website views per year

At BMC, research is always in progress.

Learn more biomedcentral.com/submissions 